\title{
Economic impact of nutritional grouping in dairy herds
}

\author{
A. S. Kalantari, L. E. Armentano, R. D. Shaver, and V. E. Cabrera ${ }^{1}$ \\ Department of Dairy Science, University of Wisconsin-Madison, Madison 53706
}

\begin{abstract}
This article evaluates the estimated economic impact of nutritional grouping in commercial dairy herds using a stochastic Monte Carlo simulation model. The model was initialized by separate data sets obtained from 5 commercial dairy herds. These herds were selected to explore the effect of herd size, structure, and characteristics on the economics and efficiency of nutrient usage according to nutritional grouping strategies. Simulated status of each cow was updated daily together with the nutrient requirements of net energy for lactation $\left(\mathrm{NE}_{\mathrm{L}}\right)$ and metabolizable protein (MP). The amount of energy consumed directly affected body weight (BW) and body condition score (BCS) changes. Moreover, to control the range of observed BCS in the model, constraints on lower (2.0) and upper (4.5) bounds of BCS were set. Each month, the clustering method was used to homogeneously regroup the cows according to their nutrient concentration requirements. The average $\mathrm{NE}_{\mathrm{L}}$ concentration of the group and a level of MP (average $\mathrm{MP}$, average $\mathrm{MP}+0.5 \mathrm{SD}$, or average $\mathrm{MP}+1 \mathrm{SD}$ ) were considered to formulate the group diet. The calculated income over feed costs gain (IOFC, $\$ /$ cow per yr) of having $>1$ nutritional group among the herds ranged from $\$ 33$ to $\$ 58$, with an average of $\$ 39$ for 2 groups and $\$ 46$ for 3 groups, when group was fed at average $\mathrm{NE}_{\mathrm{L}}$ concentration and average $\mathrm{MP}+1 \mathrm{SD}$ concentration. The improved IOFC was explained by increased milk sales and lower feed costs. Higher milk sales were a result of fewer cows having a milk loss associated with low BCS in multi-group scenarios. Lower feed costs in multi-group scenarios were mainly due to less rumenundegradable protein consumption. The percentage of total $\mathrm{NE}_{\mathrm{L}}$ consumed captured in milk for $>1$ nutritional group was slightly lower than that for 1 nutritional group due to better distribution of energy throughout the lactation and higher energy retained in body tissue, which resulted in better herd BCS distribution. The percentage of fed $\mathrm{N}$ captured in milk increased with $>1$ group and was the most important factor for improved economic efficiency of grouping strategies.
\end{abstract}

Received May 12, 2015.

Accepted October 19, 2015

${ }^{1}$ Corresponding author: vcabrera@wisc.edu
Key words: stochastic, simulation, nutritional feeding, economics

\section{INTRODUCTION}

Grouping cows is a common practice that farmers use to manage their herds more efficiently. Farmers may use various grouping strategies to separate dry cows with remote or close expected calving dates, cows that have calved recently, sick cows, pregnant cows, and first- or later-lactation cows. Grouping addresses cowspecific needs (Cabrera and Kalantari, 2014). However, grouping lactating cows for nutritional purposes and providing them with more precisely formulated diets is not an extensively adopted strategy (Contreras-Govea et al., 2015), despite the fact that many studies have shown its possible economic advantage (Coppock, 1977; McGilliard et al., 1983; Pecsok et al., 1992; Williams and Oltenacu, 1992; Stallings, 2011; Cabrera et al., 2012). Reasons that farmers do not favor nutritional grouping can be attributed to facility management limitations (such as machinery and facilities), labor cost, difficulty in managing multiple diets, and the presumption of milk production loss associated with group changes (Contreras-Govea et al., 2013, 2015). Even for farms with multiple cow groups, which would have different nutritional needs, and the capacity to feed these groups differently, all cows are often fed with a common TMR (Contreras-Govea et al., 2015). Hutjens (2013) suggests that farmers may also be concerned about introducing errors in the formulation and delivery of rations with multiple nutritional diets. In a recent survey (Contreras-Govea et al., 2015), the top reason for dairy farmers not adopting nutritional grouping was its potential management complexity.

Total mixed rations have become an industry standard for feeding management, and many dairy farms are using just 1 TMR for all lactating cows despite major differences in nutritional requirements of dairy cows in different lactation stages (Allen, 2008). For example, $58 \%$ of Wisconsin and Michigan dairy survey farms used the same TMR for all lactating cows (Contreras-Govea et al., 2015). The adoption and application of a single TMR as a common practice has resulted in more overconditioned cows in some cases, and greater nutrient excretion issues (Allen, 2009). Cows 
in similar lactation stages could have different nutritional requirements because of their productivity and genetic potential. When feeding only $1 \mathrm{TMR}$ diet, it is usually formulated for high-producing cows to ensure these cows reach their full milk production potential, which results in overfeeding of lower-producing cows. Therefore, 1 TMR diet can result in more overconditioned cows, higher nutrient excretion in the manure, and increased costs of nutrient usage. A strategy to relieve this problem is adopting nutritional groups with more precise diets, which could improve herd health, decrease environmental concerns, and increase income over feed costs due to the better-tailored diet to the cow requirements in a group. More precise diets would also improve milk productivity (Bach, 2014).

Different strategies have been explored in the literature to determine the $\mathrm{NE}_{\mathrm{L}}$ and $\mathrm{CP}$ concentrations of a diet for a group of cows, but in general, all used average milk production of a group as the basis for calculating lead factors, or the levels at which the diet should be formulated. These methods include, for example, the use of the 83rd percentile in each group (Stallings and McGilliard, 1984) or the use of differentiated levels according to several groups (Stallings, 2011). The 83rd percentile method proposes the formulation of the diet based on the $83 \mathrm{rd}$ percentile cow milk production in the group. This corresponds, approximately, to formulating the diet to 1.31 standard deviations (SD) above the average milk production for the group (1.31 lead factor; Stallings and McGilliard, 1984), assuming milk production in the group follows a normal distribution (StPierre and Thraen, 1999). The other method proposes formulation of diets based on group's milk production and number of nutritional groups such as diets for 30, 20 , and $10 \%$ above the group's average milk production for nutritional groups 1, 2, or 3, respectively (Stallings, 2011). In the current study, we go beyond milk production as proxy by using the individual cow's daily $\mathrm{NE}_{\mathrm{L}}$ and MP requirements to formulate more precise diet nutrient concentrations for the groups. Thus, in this study to formulate the $\mathrm{NE}_{\mathrm{L}}$ and $\mathrm{MP}$ concentration of the diet for different groups, we evaluated factors of SD above the average daily concentration of requirements of the cows to explore their effect on the herd's outcome.

Simulation can be a valuable tool to explore the value of nutritional grouping, which is a complex decision with many interacting factors. Simulation can handle interactions among milk production, market price, herd size, energy offered and consumed, and consequent BW and BCS changes. Indeed, simulation models have been previously developed and used to quantify the economic and environmental impact of nutritional grouping for lactating cows in a herd (Pecsok et al., 1992; Williams and Oltenacu, 1992; Østergaard et al., 1996; St-Pierre and Thraen, 1999; Cabrera et al., 2012). In the current study, we advance the modeling of nutritional grouping by using a special type of stochastic Monte Carlo simulation approach, next-event scheduling (De Vries, 2001), which can be used to model individual cows daily for a limited period. The model simulates each one of the cows in the herd and estimates their daily body energy and changes in BW and BCS. Because a nutritional grouping strategy affects the energy concentration of the diet offered and consumed, our proposed grouping model updates body energy of the cows on a daily basis by rectifying the predicted amount of energy consumed and expended, depending on current BW and BCS, DMI, and dietary energy concentration. Detailed accounting of the total net energy $\left(\mathrm{NE}_{\mathrm{L}}\right)$ consumed and used (maintenance, growth, production) by an individual is especially important in the net energy system, which the total energy intake needs to be accounted in terms of animals' products (milk, BW). We tracked all the inputs and outputs of energy within the nutritional grouping strategies studied. To the best of our knowledge, no previous study has included daily accounting of energy balance in a stochastic simulation model to explore the value of nutritional grouping in dairy cattle.

Thus, the objective of this study was to assess the economic value of nutritional grouping on 5 commercial dairy herds using a developed dynamic stochastic simulation model.

\section{MATERIALS AND METHODS}

\section{Simulation Framework}

A dynamic stochastic Monte Carlo simulation was developed to model individual cows after first parturition in a dairy herd. The next-event scheduling approach (De Vries, 2001) was used to schedule the stochastic events that could happen to cows during each reproductive cycle. First, a data set of all the cows in a herd and their current status were loaded (i.e., lactation number, day postpartum, reproductive status). Then, a list of possible stochastic events was scheduled for each cow at the beginning of the simulation and the list was renewed after starting their next lactation. These events included involuntary culling, death, pregnancy, abortion, dry-off, and parturition. For each event, a 2-step process was followed: (1) determining the binary outcome of the event (it happens or not during the cow's current lactation) and, if it happens, (2) the day of the occurrence (schedule).

The first step consists of generating a random number from a $U \sim(0,1)$ (De Vries, 2001), which is used to 
determine the outcome of an event by comparing it to a testing threshold. For example, if the probability of a cow being culled in the first lactation is 0.17 , a random number $\leq 0.17$ indicates that the cow would be culled during that lactation. The second step consists of generating another random number, from an appropriate distribution, to schedule the day on which the event would occur. For example, in the case of culling, the appropriate distribution could be obtained by creating a cumulative distribution function (CDF) from the historical data of involuntary culling distribution according to Pinedo et al. (2010). The process of scheduling the event was the same for all the events. When the underlying distribution of time of the event was known from previous studies, those standard distributions were used (Table 1). However, when the underlying distribution was unknown, an empirical distribution was used to approximate the time of the events.

After scheduling all events, every cow is evaluated daily to check if the cow matches to any specific event on a given day postpartum. If the event matches with the current day postpartum, then the cow status is updated to reflect the latest changes in the cow's attributes. For example, if a cow is $90 \mathrm{~d}$ postpartum and the cow was scheduled to be pregnant on that day, then the cow information is updated as pregnant. For culling and mortality events, replacement (with a first-calving heifer, pregnant ready to calve) is assumed to occur the next day to maintain a constant herd size over the course of the simulation.

\section{Stochastic Events}

Scheduling of culling and reproductive events are performed at the beginning of the simulation and after a cow starts a new lactation. At the beginning of the simulation, the event scheduler takes into consideration the current days postpartum of the initialized cows and schedules only possible remaining events. These events define the herd structure and are the cornerstone of the next-event scheduling simulations.

Involuntary Culling and Death. Whether or not a cow is going to finish a given lactation was based on the annualized live culling and death rate from Pinedo

Table 1. Thresholds and distributions for scheduling cow life events on the Monte Carlo model

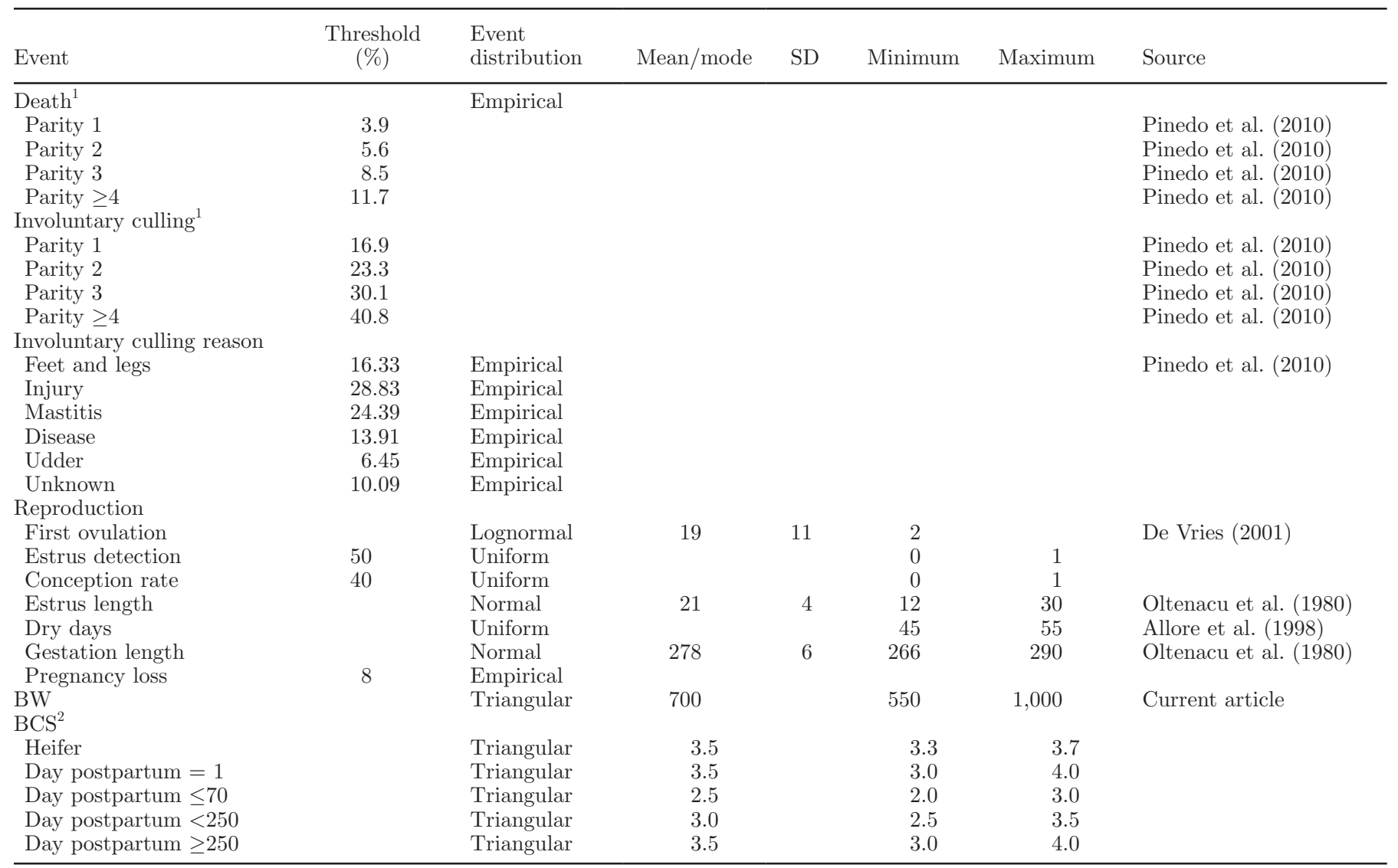

${ }^{1}$ Annualized death and live culling rates for different parities. The model accounts for different risk of culling and death based on cow parity.

${ }^{2}$ Body condition score distribution was assumed to be dependent on stage of lactation. 
et al. (2010; Table 1). For example, the threshold for death rate of the first lactation cows was set at 3.9\%, which means that $3.9 \%$ of first-lactation cows were scheduled for the death event. After knowing if a given cow would leave the herd, the reason for it needed to be determined. Also, data from Pinedo et al. (2010) were used to obtain the distribution of culling after calving for different reasons of involuntary culling. Inclusion of different reasons helped capture the fact that, based on the nature of diseases, culling could happen at different days postpartum and differently affect the herd, both economically and structurally. Thresholds for the reasons of involuntary culling were obtained by excluding the low production and reproduction reasons (voluntary culling) from the data in Pinedo et al. (2010). Then, all the involuntary culling percentages were reset to $100 \%$. These modified percentages are shown in Table 1. Then, random $U \sim(0,1)$ were generated and compared with these thresholds to determine the reason for culling. The last step was to schedule the time of the event. For this purpose, the inverse-transform method (Banks et al., 2009) was used to generate random variates from empirical distributions obtained from Pinedo et al. (2010) distribution of culling.

Besides involuntary culling, reproductive culling of nonpregnant cows was included in the model. Nonpregnant cows with days postpartum greater than the threshold (e.g., $300 \mathrm{~d}$ ) were marked as do-not-breed and were culled (reproductive failure) whenever their milk production decreased below the milk threshold (e.g., $24 \mathrm{~kg} / \mathrm{d}$ ). The cut-off days postpartum was different among farms and was implemented as an input parameter. Cows reaching the end of the 10th lactation were set to be voluntarily culled whenever their milk production decreased below the threshold.
Reproductive Events. The first occurrence of postpartum ovulation was modeled using a lognormal distribution (De Vries, 2001). Cows with days postpartum $\geq$ defined voluntary waiting period of $50 \mathrm{~d}$ were observed for estrus and had risks for breeding and conception. The estrus cycle length was determined from an $N \sim\left(21,4^{2}\right)$ distribution, truncated at 12 and $30 \mathrm{~d}$ (Table 1). Cows detected in estrus (estrus detection) and conceived (conception rate) were marked as pregnant. These rates were herd specific and are summarized in Table 2 for the 5 studied commercial dairy herds. The process of estrus detection and conception was repeated with stochastic intervals based on variable estrus cycle lengths until a cow became pregnant or reached the cut-off days postpartum (e.g., 300 d). Parturition was scheduled according to the gestation length following $N \sim\left(278,6^{2}\right)$ truncated at 266 and 290 d (Oltenacu et al., 1980). Next, the dry-off date for pregnant cows was scheduled following a $U \sim(45$, 55) (Allore et al., 1998) by back-calculation from the parturition date. The effect of extra days open on the dry period was also taken into account. An extra day was added to the dry period for each 2 open days after 120 d open (Allore et al., 1998). A herd-specific risk of pregnancy loss (Table 2) was considered from $30 \mathrm{~d}$ to term with an empirical distribution determining the day of occurrence (Giordano et al., 2012).

\section{Variation Control}

Stochastic simulation models usually need a variance reduction technique to control variation of the generated random numbers to provide precise and relevant information regarding the problem studied. This variation control is especially useful when the

Table 2. Input dairy herd characteristics and structure at the beginning of the simulation $(\mathrm{d}=0)$

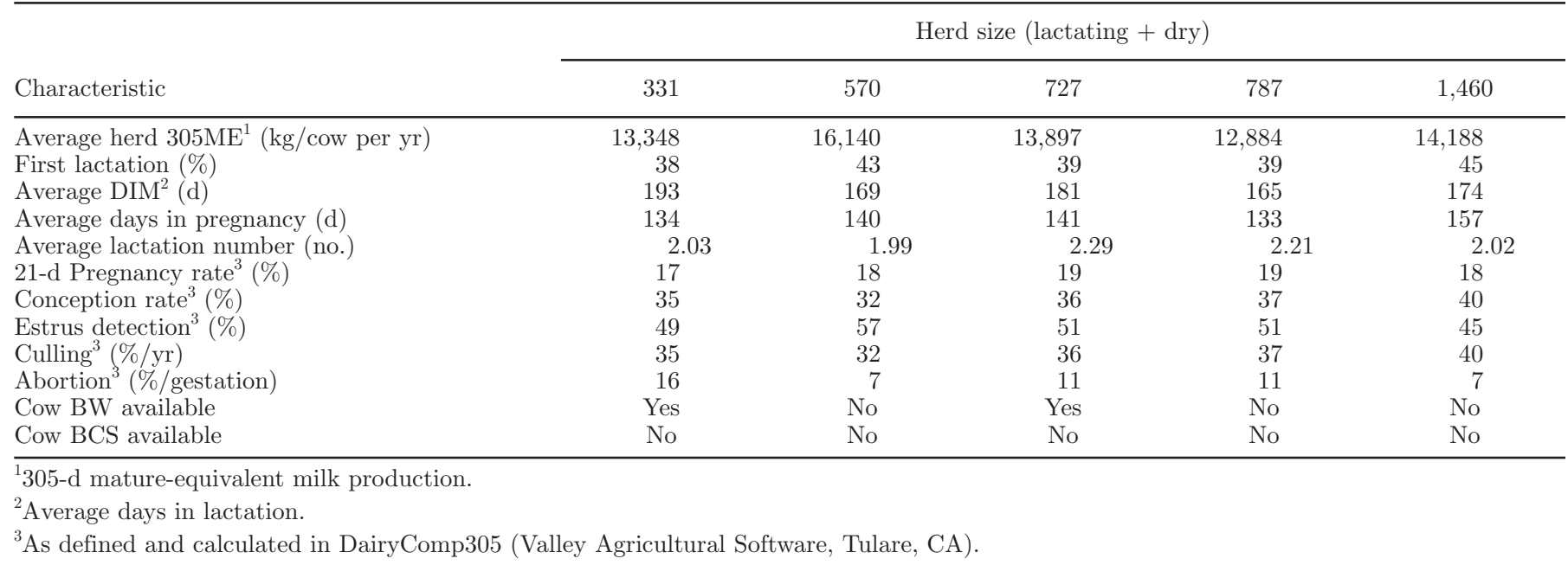


model is large and takes considerable computational time to solve (Hillier and Lieberman, 1986) as was the case in this study. Therefore, a synchronized common random numbers method was used (Banks et al., 2009) to control the variation due to differences in generated random numbers. In this method, the same stream of random numbers (common random numbers) is used for the same purposes (synchronized) among different scenarios of the model. This method diminished the need for a large number of replications to reduce the standard deviation of outcomes.

\section{Computer Implementation}

An object-oriented design was used to assist in the design process and implementation of the Monte Carlo simulation. Object-oriented design principles were followed in a 2-step process to build the model. First, all the important components of the herd related to nutritional grouping were identified. The main goal of this step was to recognize important objects in a real herd that could play an important role in a nutritional grouping and define them as objects; that is, herds, cows, groups, and TMR. Second, object-oriented programming, a method of implementing a conceptual model to a computer program, was used to build the model (Shaffer et al., 2000). Java 1.7, a concurrent and general object-oriented programming language, was used to implement the model. The model benefited from concurrent characteristics of Java to run replications of a given herd simultaneously, which was especially useful in decreasing the running time.

\section{Objects}

Objects relevant to nutritional grouping were herd, cow, group, and TMR (Figure 1). The process of acquiring data from the input herds and the data flow inside the program is illustrated in Figure 1A. The following sections describe attributes related to the other objects named in Figure 1A.

Herd. The underlying object in the model is the herd. The herd object stored some of the input parameters that are shared among herds, such as the simulation period (number of days to simulate the herds) and prices (milk price and TMR related prices). Figure 1A summarizes important attributes used to define a herd in the model. These attributes were initialized based on the real herd characteristics.

Cow. A cow is described by a series of state variables (attributes). These attributes are summarized in Figure 1A. After initializing a herd, cows were instantiated and added to the herd based on the input file. An input file, a snapshot from current adult cows (lactating and dry cows) of a commercial herd, was read and stored in a database of all the cows. Variables included in the input file were: cow identification, parity, days postpartum, days in pregnancy, fat percentage, protein percentage, 305-d mature-equivalent yield (305ME), BW (if available), and BCS (if available).

\section{Cow Attributes}

The following sections describe the methods used to calculate and update different attributes of an individual cow on a given lactation and days postpartum throughout the simulation. Some of these attributes were held constant for the lifetime of a cow (e.g., milk potential), and some were changed based on the lactation and days postpartum (e.g., lactation curves). Thresholds and distributions used for determining the outcomes of an event and its corresponding time of occurrence are summarized in Table 1 and the process is described in the simulation framework.

Milk, Fat, and Protein Production. Cows in the herd were categorized based on their 305ME. Level of milk production for a cow was estimated based on the cow's 305ME relative to the average 305ME of a herd. This attribute is named "milk potential" in Figure 1A. This value captured the level of milk production of a cow compared with herd mates and was held constant over the simulation period.

After setting a relative level of production for each cow, the incomplete gamma function (Wood, 1967) was used to calculate daily milk production of a cow. First, second, and later lactations used different prediction curves of milk production. These parameters were estimated based on the reference milk curves obtained from DHI records (AgSource Cooperative Services, 2013). All the herds in the study shared the same shape of lactation curve. This was done to decrease the dominating effect of milk production on the outcomes of the model. However, every single cow had different milk production, because its production was relative to its herd mates and the herd average. Additionally, a random dependent milk production error was added based on Allore et al. (1998) and De Vries (2001) to capture the possible daily fluctuation of milk production for each cow. Milk production was also adjusted to decrease by constant factors of 5,10 , and $15 \%$ by months of pregnancy 5, 6, and 7, respectively (De Vries, 2004). Modified Wood's curves, for better fit as described in De Vries (2001), were used to estimate the milk fat and protein percentages during lactations based on the cow's initial fat and protein production from the input herds. Milk potential of pregnant replacement heifers was assumed to follow $N \sim(100,10.02)$ based on van Arendonk (1985). 

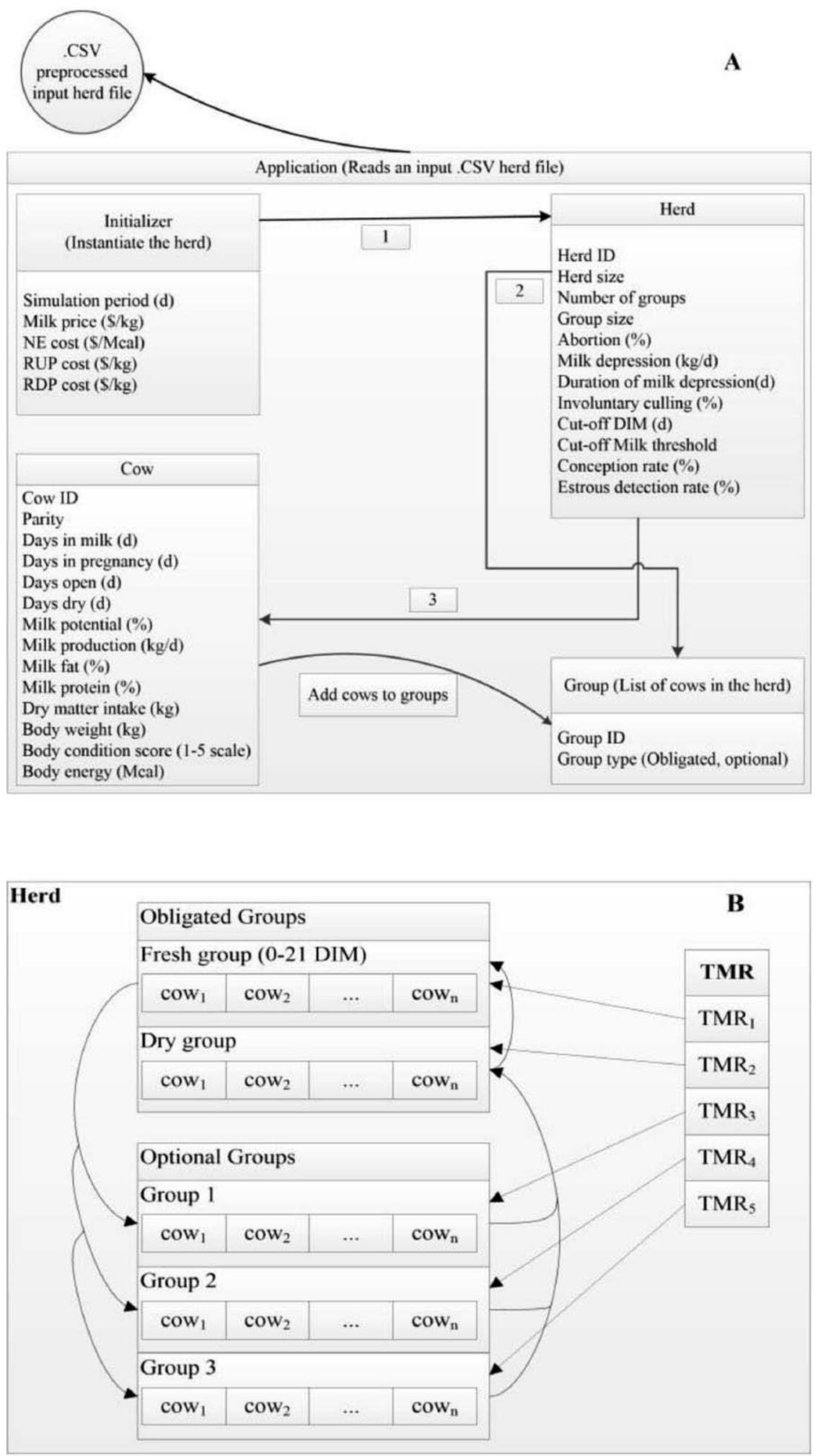

Figure 1. Diagram flow of simulation modeling framework. Panel A: The main application reads a preprocessed input file and then Initializer (1) is used to instantiate the herd object. Following completion of this process, groups are created (2), and cows are initialized based on the input cows from a herd (3). Finally, these cows are added to the appropriate group (obligated or optional). Panel B is a schematic representation of a herd with 3 optional groups for lactating cows. At the beginning of the simulation (d 0) and at the end of each month, the cows are ranked based on their nutritional requirements, are regrouped among the optional groups, and fed a TMR formulated based on group requirements Depending on their state, cows move into a dry group or a fresh group. 
$\boldsymbol{B} \boldsymbol{W}$ and $\boldsymbol{B C S}$. The initial BW and BCS for an individual cow could come from dairy herd records or from distributions. For those herds without BW or BCS records, a triangular distribution was used to generate the initial BW and BCS at the beginning of the simulation. Triangular distribution for BW was based on 794 available BW records from 2 Holstein farms. Based on these data, the minimum BW was set at 550, the maximum at 1,000, and the most likely at $700 \mathrm{~kg}$ : $T \sim(550,700,1,000)$. These calculated BW were used as the mature BW (MW) for each cow in the herd, and factors of 0.82 and 0.92 were used to set the current BW (BW at the start of the simulation) for the firstand second-lactation cows, respectively (NRC, 2001). Then, the difference between current BW and MW was used to estimate the ADG needed for the first- and second-lactation cows to reach their MW, as follows (NRC, 2001):

$$
\begin{gathered}
\text { First lactation: ADG }(\mathrm{kg} / \mathrm{d})=\{[\mathrm{MW}(\mathrm{kg}) \\
\times 0.92]-\mathrm{BW}(\mathrm{kg})\} / 300, \text { and }
\end{gathered}
$$

$$
\begin{gathered}
\text { Second lactation: ADG }(\mathrm{kg} / \mathrm{d})=[\mathrm{MW}(\mathrm{kg}) \\
-\mathrm{BW}(\mathrm{kg})] / 300,
\end{gathered}
$$

where BW is the current BW. We assumed that cows use the consumed energy for growth after passing the average negative energy balance period at the beginning of the lactation ( $65 \mathrm{~d}$ postpartum). Thus, $65 \mathrm{~d}$ was deducted from an average calving interval of $365 \mathrm{~d}$ to uniformly distribute the net weight gain (growth) over a current lactation. Third and later lactation cows were assumed to be at their MW. For initializing BCS, different triangular distributions were used based on the cow's days postpartum. For primiparous cows entering the herd, a less variable distribution of $T \sim(3.3,3.5,3.7)$ was used. For other cows, the expected BCS based on their days postpartum was used. Distribution parameters used for BCS and the range of days postpartum are summarized in Table 1.

After setting the initial values for BW and BCS, these values were used to find the total body energy (BE) of each cow in the herd based on NRC (2001; p. 24) equations. The estimated BE enabled the model to keep track of excess or deficiency in energy intake of an individual cow based on the energy provided by the diet on a daily basis. Moreover, this BE was used to predict the $\mathrm{BW}$ and $\mathrm{BCS}$ of each cow in the herd over time.

To capture the relationship between $\mathrm{BE}$ and standard BW (standardized at BCS 3.0), 13 samples of $\mathrm{BE}$ for cows at different sizes and BCS were generated (from 400 to $1,000 \mathrm{~kg}$ with $50-\mathrm{kg}$ intervals and over 5 BCS scores with 0.01 increments) based on NRC (2001) equations. These samples were used in a 2-step regression analysis as follows: first, a third-order polynomial regression was used to predict $\mathrm{BW}$ from the $\mathrm{BE}$ of a cow on available 13 samples of generated body weights, as follows:

$$
\mathrm{BW}(\mathrm{kg})=\beta_{0}+\beta_{1} \mathrm{BE}^{3}+\beta_{2} \mathrm{BE}^{2}+\beta_{3} \mathrm{BE} .
$$

Applying Eq. [3] on 13 samples available provided 13 different regression lines. Each parameter in Eq. [3] was examined to capture the trend in the parameter changes across BW. The linear term $\left(\beta_{3}\right)$ was constant across BW, whereas the intercept changed linearly; therefore, these coefficients were found for a given BW and $\mathrm{BE}$ of a cow. Obviously, the high-order terms $\left(\beta_{1}\right.$, $\beta_{2}$ ) were curvilinear. Second, using this information a fifth-order polynomial regression was used to capture the essence of changes of parameters $\left(\beta_{1}, \beta_{2}\right)$ in Eq. [3]:

$$
\begin{aligned}
\beta_{1,2}=\alpha_{0} & +\alpha_{1} \mathrm{BW}^{5}+\alpha_{2} \mathrm{BW}^{4}+\alpha_{3} \mathrm{BW}^{3} \\
& +\alpha_{4} \mathrm{BW}^{2}+\alpha_{5} \mathrm{BW} .
\end{aligned}
$$

Equation [4] was used to predict 2 terms $\left(\beta_{1}, \beta_{2}\right)$ of Eq. [3] and the intercept and linear terms were calculated and applied for a given standard BW and BE of a cow to predict a new BW for a cow based on Eq. [3]. The same process was used to predict the BCS of cows based on their BE. Use of higher-order polynomial ensured an invariant prediction of BW and BCS from BE $\left(\mathrm{R}^{2}=1.0\right)$. The described method was used to capture all the changes in $\mathrm{BE}$ of a cow based on the consumed energy and to predict the resulting synchronized BW and BCS. For first- and second-lactation cows, BW change was calculated by adding the ADG (estimated from Eq. [1] and [2]) to the current BW after 65 DIM. These procedures tracked the balance of energy and the changes in BW and BCS throughout the life of each cow in the herd on a daily basis.

To control the BCS range, some lower and upper bounds were set. The lower bound was set at 2.0. Cows with BCS that would fall below this were assumed to stay at this BCS $(=2.0)$ but at a decreased milk production new daily milk $(\mathrm{kg} / \mathrm{d})=$ daily milk $(\mathrm{kg} / \mathrm{d})-$ [deficient $\mathrm{NE}_{\mathrm{L}}(\mathrm{Mcal} / \mathrm{d}) / \mathrm{NE}_{\mathrm{L}}$ in Milk (Mcal/ $\mathrm{kg})]\}$. The upper bound was set at 4.5. Cows that would exceed this BCS were assumed to stay at this BCS (= 4.5) but decreased their DMI nnew DMI $(\mathrm{kg} / \mathrm{d})=\mathrm{DMI}$ $(\mathrm{kg} / \mathrm{d})-\left[\operatorname{extra} \mathrm{NE}_{\mathrm{L}}(\mathrm{kg} / \mathrm{d}) /\right.$ dietary $\left.\left.\mathrm{NE}_{\mathrm{L}}(\mathrm{Mcal} / \mathrm{kg})\right]\right\}$. In summary, when cows reached a BCS of 2.0 or 4.5 , milk energy excretion and $\mathrm{NE}_{\mathrm{L}}$ intake were set equal. This was regulated by limiting milk for cows with BCS 
dropping below 2.0, and limiting intake for cows with BCS exceeding 4.5.

\section{Deterministic Parameters:}

Daily DMI was calculated using the NRC (2001; p. 4) equation, which is a function of $\mathrm{BW}$ and FCM production with an adjustment for decreased DMI during the early postpartum period.

\section{Cow Nutrient Requirements}

Net Energy. Total net energy requirement of a cow was calculated by aggregating the requirements for maintenance $\left(\mathrm{NE}_{\mathrm{M}}\right)$, milk production $\left(\mathrm{NE}_{\mathrm{L}}\right)$, and growth $\left(\mathrm{NE}_{\mathrm{G}}\right)$ based on NRC (2001) equations. The calculated total daily required net energy $(\mathrm{Mcal} / \mathrm{d})$ was divided by the DMI of each cow to find the dietary net energy concentration requirements (Mcal $/ \mathrm{kg}$ of DM).

Metabolizable Protein. Metabolizable protein is more representative of the protein value of the diet and the cow's specific requirements (Varga, 2010) and was used instead of CP. The total MP requirement was calculated by aggregating the MP requirements of maintenance $\left(\mathrm{MP}_{\mathrm{M}}\right)$, milk production $\left(\mathrm{MP}_{\mathrm{L}}\right)$ and growth $\left(\mathrm{MP}_{\mathrm{G}}\right)$ based on NRC (2001) equations. The total MP, furthermore, was divided into RDP and RUP.

Nitrogen Captured in Milk. Nitrogen captured in milk for each herd was estimated by calculating the total $\mathrm{N}$ excreted in milk and dividing it by the total $\mathrm{N}$ ingested in the diet:

$$
\begin{gathered}
\text { MilkN }=[\operatorname{milkY}(\mathrm{kg}) \times \operatorname{milkPr}(\%) / 6.38] / \\
{[\mathrm{DMI}(\mathrm{kg}) \times \mathrm{CP}(\%) / 6.25]}
\end{gathered}
$$

where milkN is the percentage of nitrogen in milk (\%); milkY $=$ milk yield; milkPr is the protein percentage in milk, and $\mathrm{CP}$ is the percentage of $\mathrm{CP}$ in the diet. The $\mathrm{CP}$ percentage was calculated by adding up RDP and RUP after considering $80 \%$ digestibility for RUP.

\section{Grouping Dynamics}

A group of cows share a common diet. The model distinguished 2 types of groups: obligated and optional. Obligated groups consisted of a group for dry cows and another group for fresh cows (under $22 \mathrm{~d}$ postpartum). Obligated groups were considered standard in all herds and not part of the analysis of nutritional grouping. Figure 1B depicts a schematic representation of the groups and the flow of the cows among the groups. Cows in the fresh and dry groups were fed based on a constant $\mathrm{NE}_{\mathrm{L}}$ of 1.7 and $1.28 \mathrm{Mcal} / \mathrm{kg}$ of $\mathrm{DM}$, respec- tively. For all other lactating cows, $\mathrm{NE}_{\mathrm{L}}$ was based on the group with a maximum $\mathrm{NE}_{\mathrm{L}}$ concentration of 1.79 $\mathrm{Mcal} / \mathrm{kg}$, which represents a practical upper limit on dietary energy concentration maximum limits based on diet NFC contents and minimum limits on diet total NDF and forage NDF contents according to NRC (2001). The MP concentration of requirements (g/100 $\mathrm{g}$ of $\mathrm{DM}$ ) for the fresh cows was estimated based on the 83rd percentile of the requirements in this group of cows, and this value for dry cows was set at $7 \mathrm{~g} / 100 \mathrm{~g}$ of DM (approximately 1,000 g/d recommended amount for an average mature cow). Cows in the fresh group were moved to an optional group after $21 \mathrm{~d}$ postpartum. Optional groups were used to test the effect of nutritional grouping on the overall income over feed costs (IOFC; based on RDP, RUP, and energy costs per $\mathrm{kg}$ of DM) and efficiency of the nutrients used in milk production by the cows.

The number of optional groups was variable and altered to test the economic effects of several nutritional groups in different herds. To be consistent among herds, the sizes of optional groups were chosen to be approximately equal among them (total available cows were divided by the number of defined nutritional groups). Optional group size was set at model initialization. The model first assigned a maximum size based on the total number of available cows in the herd to all the optional groups. Later, the model followed the cows and moved them among the groups as required. Consequently, throughout the simulation, the number of cows in each group could vary from the initial starting point because of cow movements from optional groups to obligated ones or vice versa. Thus, it was assumed the group size changes continually based on the status of available cows in the herd.

The monthly regrouping process of optional groups started by ranking the cows based on their $\mathrm{NE}_{\mathrm{L}}$ and MP requirements (clustering method; McGilliard et al., 1983). This method minimizes the within-group variability of individual animal nutrient requirements expressed as the concentration of $\mathrm{NE}_{\mathrm{L}}$ and $\mathrm{MP}$ in the diet. The next step was to determine all the permutations of the current group sizes. Then, the model iterated over all these permutations and calculated the initial IOFC for each arrangement of the cows inside the group. This last process was used to assign the cows to groups in a way that maximized the IOFC of the herd at that point in time. In other words, the permutation step was to make sure that the determined diets from clustering are given to the groups that maximize the temporary IOFC of all the optional groups. In addition, inside this iteration, the average $\mathrm{NE}_{\mathrm{L}}$ and $\mathrm{MP}$ concentrations of the requirements were calculated for the group. Then, the diet for the group was formulated based on average 
$\mathrm{NE}_{\mathrm{L}}$ requirements of the group. Different levels of $\mathrm{NE}_{\mathrm{L}}$ concentrations, average $\mathrm{NE}_{\mathrm{L}}$, average $\mathrm{NE}_{\mathrm{L}}+0.5 \mathrm{SD}$ and average $\mathrm{NE}_{\mathrm{L}}+1 \mathrm{SD}$, were considered. We found that formulating the diet for above the average $\mathrm{NE}_{\mathrm{L}}$ concentration changed the BE contents of the cows in the herd, resulting in an undesirable proportion of obese cows in the herd (data not shown). For that reason, only average $\mathrm{NE}_{\mathrm{L}}$ concentration was used. Regarding $\mathrm{MP}$, the base scenario used MP+1SD, but because MP concentration does not affect BCS, 2 other scenarios were also studied - average MP and average MP+0.5SD.

TMR. This was the object in the model that contained the information regarding the TMR fed to each group at each regrouping during the simulation time, which was set at the regrouping time (every month). More specifically, TMR was a list of $\mathrm{NE}_{\mathrm{L}}$ and $\mathrm{MP}$ provided in the diet for each nutritional group every month.

\section{Economic Parameters}

Economic parameters for the base scenario of calculating IOFC were set as 10-yr Wisconsin average prices from 2005 to 2014 . Thus, milk price was set to $\$ 0.39$ / $\mathrm{kg}$ of milk. For feed prices, corn and soybean meal with available 10-yr historical prices were used to set all other feed commodity prices. Relative price of 24 commodities in April 2015 in relationship to corn and soybean meal was calculated and used to set their 10yr historical average price. Ten-year historical averages (2005-2014) of 26 default commodities in the FeedVal 6.0 model (http://dairymgt.info/tools.php) was used to calculate the nutrient prices of $\mathrm{NE}_{\mathrm{L}}, \mathrm{RDP}$, and RUP. The calculated nutrient prices were: $\$ 0.1 / \mathrm{Mcal}$ of $\mathrm{NE}_{\mathrm{L}}$, $\$ 0.18 / \mathrm{kg}$ of RDP, and $\$ 1.04 / \mathrm{kg}$ of RUP. These values were used as the typical price for the base scenario runs.

\section{Scenario Analyses}

To explore the effects of different milk and nutrient prices on the economic value of nutritional grouping, extreme differences between these input variables were explored. For this purpose, 2 extreme scenarios were developed. The worst case scenario was designed by coupling the lowest milk price with the highest nutrient costs and vice versa for the best case scenario. Ten-year annual average of milk price was used to set the highest $(\$ 0.52 / \mathrm{kg})$ and lowest milk $(\$ 0.29 / \mathrm{kg})$ prices. For the nutrient costs, the same approach as described above was used to find the highest and lowest nutrient prices. The highest (lowest) nutrient costs were set at $\$ 0.14$ / Mcal of $\mathrm{NE}_{\mathrm{L}}(\$ 0.05), \$ 0.26 / \mathrm{kg} \mathrm{RDP}(\$ 0.09)$, and $\$ 1.52$ / kg RUP (\$0.52).
Different field trials have shown different amounts and durations of milk losses due to grouping. Some studies from the 1970s showed a high amount of milk loss of 1 to $2 \mathrm{~kg} /$ cow per day for a long period (13 to 37 wk; Smith and Coppock, 1974; Smith, 1976; Smith et al., 1978). In these studies, the group change was coupled with a sudden change in the level of forage and concentrates in the diet. Brakel and Leis (1976) reported a $0.51-\mathrm{kg}$ or $3 \%$ decrease in $4 \% \mathrm{FCM}$ of 4 moved cows to groups of 20 cows, but only during d 1 of the move. Hasegawa et al. (1997) reported a $4.7 \%$ milk yield decrease during the second week after moving half of the cows between 2 pens of primiparous cows. von Keyserlingk et al. (2008) placed a new cow into a small established group of 11 cows, and reported a decrease in milk yield of the moved cow of $3.7 \mathrm{~kg}$, but only during $d 1$ of the move. Other researchers did not find changes in milk yields (Clark et al., 1977). More recently, Zwald and Shaver (2012) showed no deleterious effect due to grouping, when there was plenty of food and bunk space available and groups were large (>60 cows). Considering these differences among studies, possible milk loss due to regrouping lactating cows was explored with a base scenario without any milk loss and another scenario with extreme milk losses of 1.82 $\mathrm{kg} / \mathrm{d}$ for $5 \mathrm{~d}$ (Cabrera and Kalantari, 2014).

In addition, the effect of having first-lactation cows as a separate nutritional group was explored as another scenario because this is a common practice in several commercial herds (Contreras-Govea et al., 2015). In this scenario, first-lactation cows formed an obligatory group and were fed based on the nutrient concentration requirements of the cows in the group similar to the optional groups.

\section{Case Study Herds and Projection Timeline}

The 5 sets of initial herd characteristics for this case study are summarized in Table 2. Holstein herds from Wisconsin with different sizes were chosen. The size of the herds was an important criterion in this study, which ranged from 331 to 1,460 adult cows. All herds used a TMR feeding management system. The model captured current herd profiles ( $\mathrm{d}=0$ of the simulation) and then projected individual cow and herd performance daily for a year $(\mathrm{d}=365)$.

The model was run on data from 5 input herds for 1,000 replications, with different instances of the herd being simulated, and both herd dynamics and economic outputs were stored as comma-separated files for further aggregation to report key figures and statistics. Results are presented interchangeably for selected herds because outcomes were similar among different studied herds. 


\section{RESULTS AND DISCUSSION}

\section{Model Evaluation}

Different functionalities of the model were verified and evaluated to test the behavior of the model on the input farms. The evaluation was based on graphs and summary statistics comparing the model to the original herds and industry standard values. Selection of these statistics and visualizations are presented in Table 3 and Figure 2. Table 3 summarizes the obtained herd statistics and structure after a year of simulating 5 input herds. Herd summary statistics of the model projections after a year of daily iterations are comparable with the statistics of the input herds and industry averages. Note that the average herd milk production in Table 2 (input values) and Table 3 (model results) differ considerably. The main reason for this is that we used the same milk production function parameters for all herds to limit the effect of milk production on the economic results of the model. Variations in the rolling herd averages among the herds as observed in Table 3 are due to individual cow milk production potential differences among the herds. Other parameters in Table 3 are within ranges plausible in the industry, and the model appears to produce reasonable outcomes. The most important unavailable data that could greatly affect the projections include (1) individual farm culling pattern and frequencies, (2) culling policies related to reproductive failure, and (3) the specific reproductive program used on the farm. Even with these limitations, reproductive parameters such as average days in pregnancy and average estrous detection and 21-d pregnancy rates were close to the input herd values (Table 2). In general, herd management and practices (e.g., herd expansion) are not known to the model and therefore similar herd statistics at the beginning of the simulation might not be expected after a year of simulation.
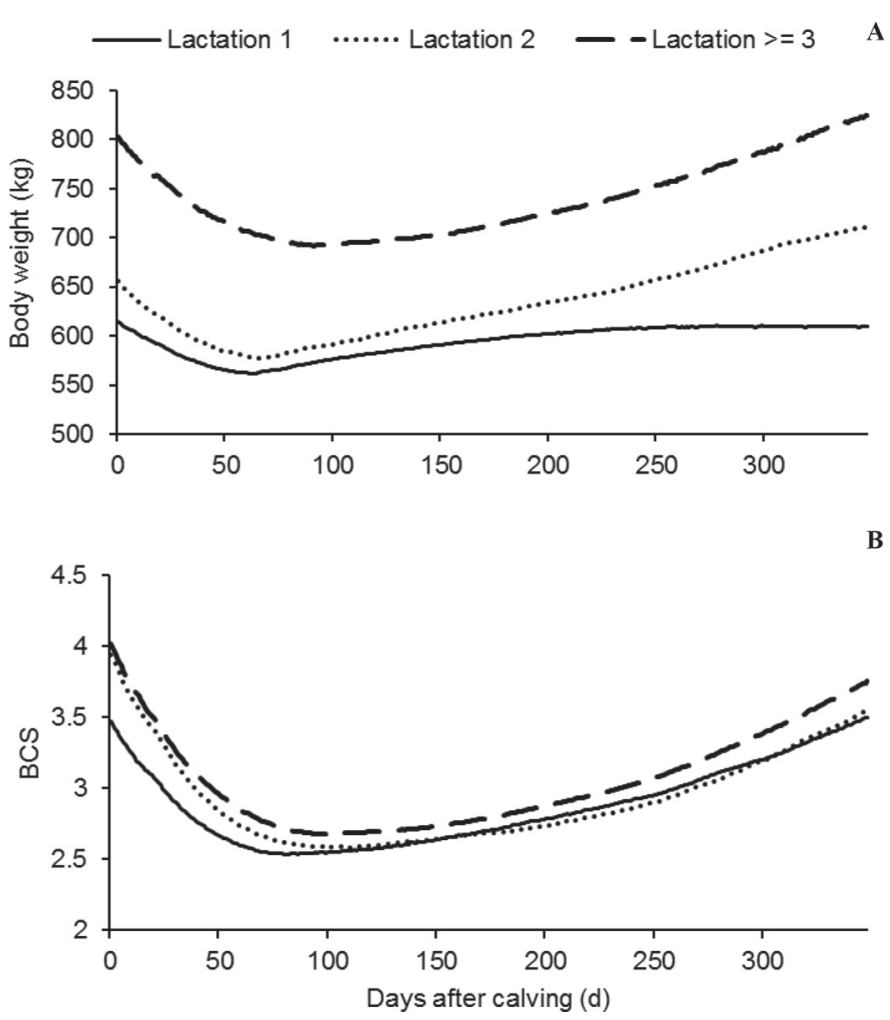

Figure 2. (A) Average BW change after calving for first-, second-, and $\geq$ third-lactation cows; (B) average BCS change for first-, second-, and $\geq$ third-lactation cows obtained from 1,000 replication of a 1,460cow herd with one nutritional group.

Another part of the model, which was highly related to the effects of the nutritional grouping, were the modules calculating BW and BCS of the lactating cows. Both of these were affected by BE, which depended on the energy consumed and the stage of lactation. The average changes (over 1,000 replications) in BW and $\mathrm{BCS}$ of the cows fed in only 1 nutritional group are illustrated in Figure 2A and 2B. The shape, trend, and values for BW and BCS are similar to those depicted

Table 3. Herd structure and dynamics [mean (SD)] after a year over 1,000 replications of different input herds

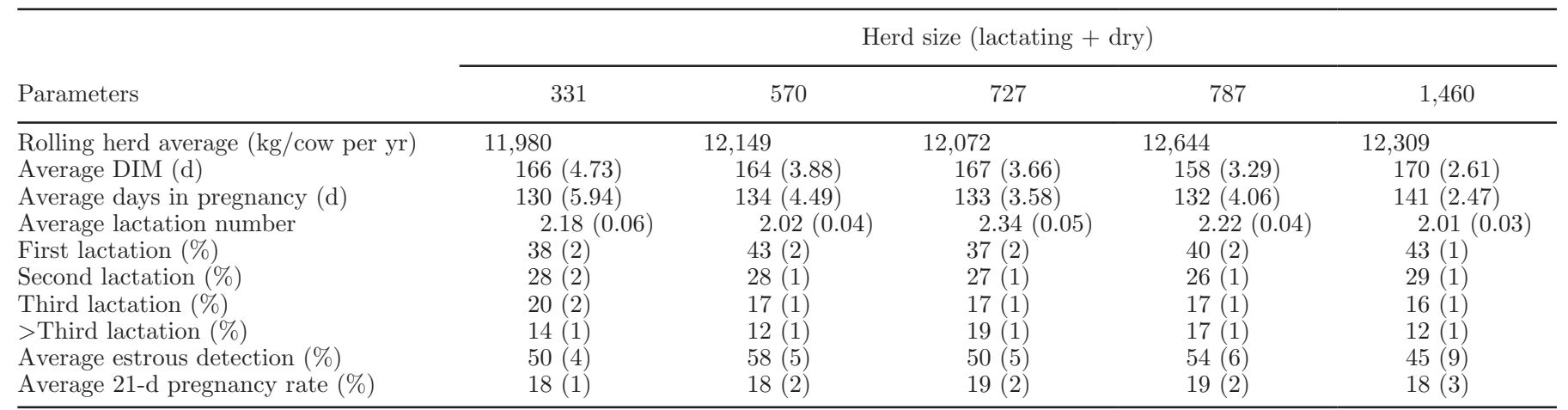


in NRC (2001) and the curves obtained from using the Korver function for BW prediction (Cabrera et al., 2012). Based on these evaluations, the model seems to give consistent and plausible results and can be used to evaluate the economic impacts of nutritional grouping in dairy cows. It should be noted that the provided summary statistics for the herds and figures of BW and BCS are considered to be only verification of the model. Validating the economic results of the study would require running a field trial study in parallel to the simulation model to test the goodness of estimation of the model compared with real observed values from the field trial. Due to the lack of such field trial data, the model cannot be considered validated. Nonetheless, we consider the model results valid for our study purposes.

\section{Grouping}

Lactating cows of the optional groups after the fresh period ( $>21$ d postpartum, 592 cows) from a 787-cow herd at $300 \mathrm{~d}$ in the simulation are shown in Figure 3 ranked according to their $\mathrm{NE}_{\mathrm{L}}$ concentration requirements. It is clear that lactating cow requirements vary substantially on a given day because of differences in days postpartum, pregnancy status, BW, and milk production. In this example, the highest $\mathrm{NE}_{\mathrm{L}}$ concentration requirement was from a cow in third lactation, 23 d postpartum, with a milk yield $20 \%$ above herd average. The lowest $\mathrm{NE}_{\mathrm{L}}$ concentration requirement was from a cow in third lactation, $385 \mathrm{~d}$ postpartum, with $10 \%$ below average milk yield. To cope with this high variability, precision feeding according to an individual cow's requirements would be ideal but unfortunately is not yet practical, especially in larger herds (Sniffen et al., 1993). On the other hand, preparing a diet of just 1 TMR for all cows could result in large overfeeding or underfeeding problems. A diet is usually formulated for high-producing cows to ensure that milk production is maintained (Weiss, 2014) but feeding the group with just 1 TMR is inefficient from a nutrient use standpoint. A practical way to overcome this high variability is to group them according to their requirements. The effect of grouping these 592 lactating cows (from a 787cow herd) is illustrated in Figure 4 where the difference between offered and the required $\mathrm{NE}_{\mathrm{L}}$ concentrations (offered $\mathrm{NE}_{\mathrm{L}}$ - required $\mathrm{NE}_{\mathrm{L}}, \mathrm{Mcal} / \mathrm{kg}$ ) are depicted for 3 cases of nutritional groupings. Figure 4 shows that when feeding all the cows as one group and formulating the diet based on the average $\mathrm{NE}_{\mathrm{L}}$ concentration of the group, approximately half of the cows are overfed and the other half underfed. However, it should be noted that the $\mathrm{NE}_{\mathrm{L}}$ concentration of the requirements is not necessarily normally distributed. Thus, formulating based on the average $\mathrm{NE}_{\mathrm{L}}$ concentration does not al- ways result in overfeeding half the cows and underfeeding the other half. We observed that the distribution was strongly affected by herd structure at the point of regrouping the cows. Specifically, it depended on the percentages of fresh animals that were moving into optional groups $(>21 \mathrm{~d}$ postpartum $)$ - cows with the highest requirements - which caused right skewedness in the distribution. It was also dependent on the percentages of late-lactation cows moving to the dry group, which caused left skewedness in the distribution. Figure 4 shows that increasing the number of groups decreases the variability among the cows within the group, which is especially beneficial in offering the cows a diet closer to individual cow requirements in terms of health, environment, and economics. This benefit is more pronounced in the case of large herds and when the distribution of the requirements is not normal (McGilliard et al., 1983). The difference between offered and required MP for the cows in the group when feeding the group of cows average $\mathrm{MP}+1 \mathrm{SD}$ shows a pattern similar to that for $\mathrm{NE}_{\mathrm{L}}$ (data not shown). The only difference in the case of MP+1SD is the smaller number of cows being underfed MP compared with $\mathrm{NE}_{\mathrm{L}}$. All additional discussion points for the $\mathrm{NE}_{\mathrm{L}}$ also apply to MP.

\section{Economic Value of Nutritional Grouping}

The economic value of nutritional grouping measured in terms of IOFC is displayed as the difference from 2 to 4 nutritional groups and 1 nutritional group for different levels of MP provided in the diet (average MP, average $\mathrm{MP}+0.5 \mathrm{SD}$, and average $\mathrm{MP}+1 \mathrm{SD}$ ) in Figure 5 . It is clear that an economic gain results from nutritional grouping. These gains depended on the number of groups and varied from ( $\$ /$ cow per yr) $\$ 39$ for 2 groups, to $\$ 46$ for 3 groups, to $\$ 47$ for 4 groups when the diet had average MP+1SD concentration (Figure 5). This gain also depended on the MP concentration in the diet, and it was lowest when the cows were offered an average MP concentration of the group (approximately $\$ 15 /$ cow per yr) and highest at average concentration $\mathrm{MP}+1 \mathrm{SD}$ (approximately $\$ 44 /$ cow per yr). This was mainly because RUP had the highest nutrient cost, and offering a greater concentration of it in the diet would further accentuate the potential benefit of applying nutritional groups. For the rest of this paper, we use $\mathrm{MP}+1 \mathrm{SD}$ to illustrate the effect of grouping cows.

The gain in IOFC with more nutritional groups was due to higher milk production and lower feed costs. Higher milk production for more than 1 group was due to fewer cows having milk loss for low BCS (BCS <2.0). The lower feed costs with 2 and 3 groups were mainly due to less RUP cost (Figure 5). Compared with RUP cost, other components of IOFC (RDP and $\mathrm{NE}_{\mathrm{L}}$ costs 


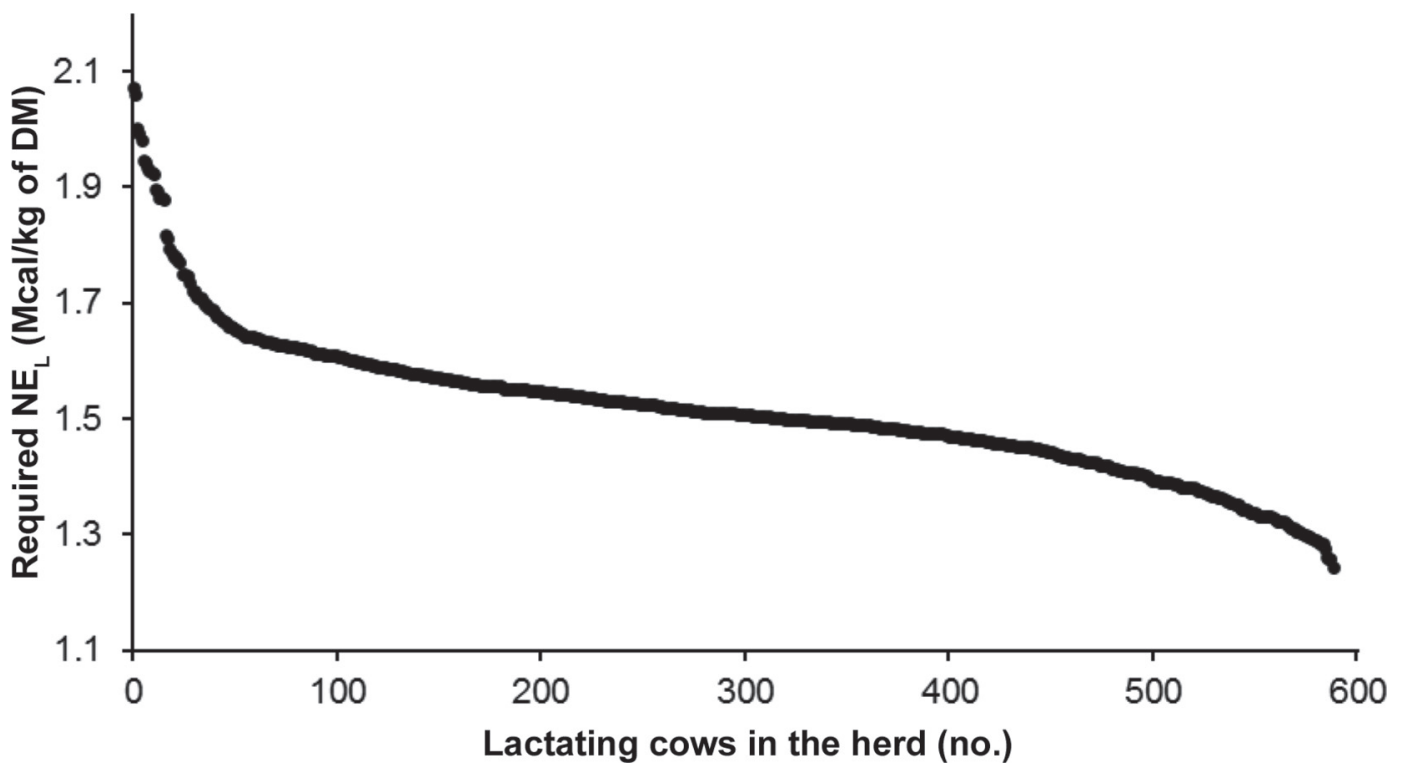

Figure 3. Required $\mathrm{NE}_{\mathrm{L}}$ concentration of 592 lactating cows (all lactating cows minus fresh cows $<22$ d postpartum) from the 787-cow herd at $\mathrm{d}=300$ of simulation.

and milk revenue) were more stable across different grouping numbers and MP concentrations in the diet.

Regardless of herd size, the largest relative IOFC gain was obtained when moving from 1 group to 2 groups. After 2 groups, the gain was less. Comparing 1 group and 2 groups, the IOFC gain ranged (\$/cow per yr) from $\$ 33$ (570-cow herd) to $\$ 49$ (787-cow herd) when average $\mathrm{MP}+1 \mathrm{SD}$. The overall (average of 5 herds in the study) gain in IOFC ( $\$ /$ cow per yr) from 1 group to 2 groups was $\$ 39 \pm 6$ and from 1 group to 3 groups was $\$ 46 \pm 7$ (Figure 5). Economic gains found in other studies are different because of differences in the model and the input values used in those studies. For example, Williams and Oltenacu (1992) reported that the mean

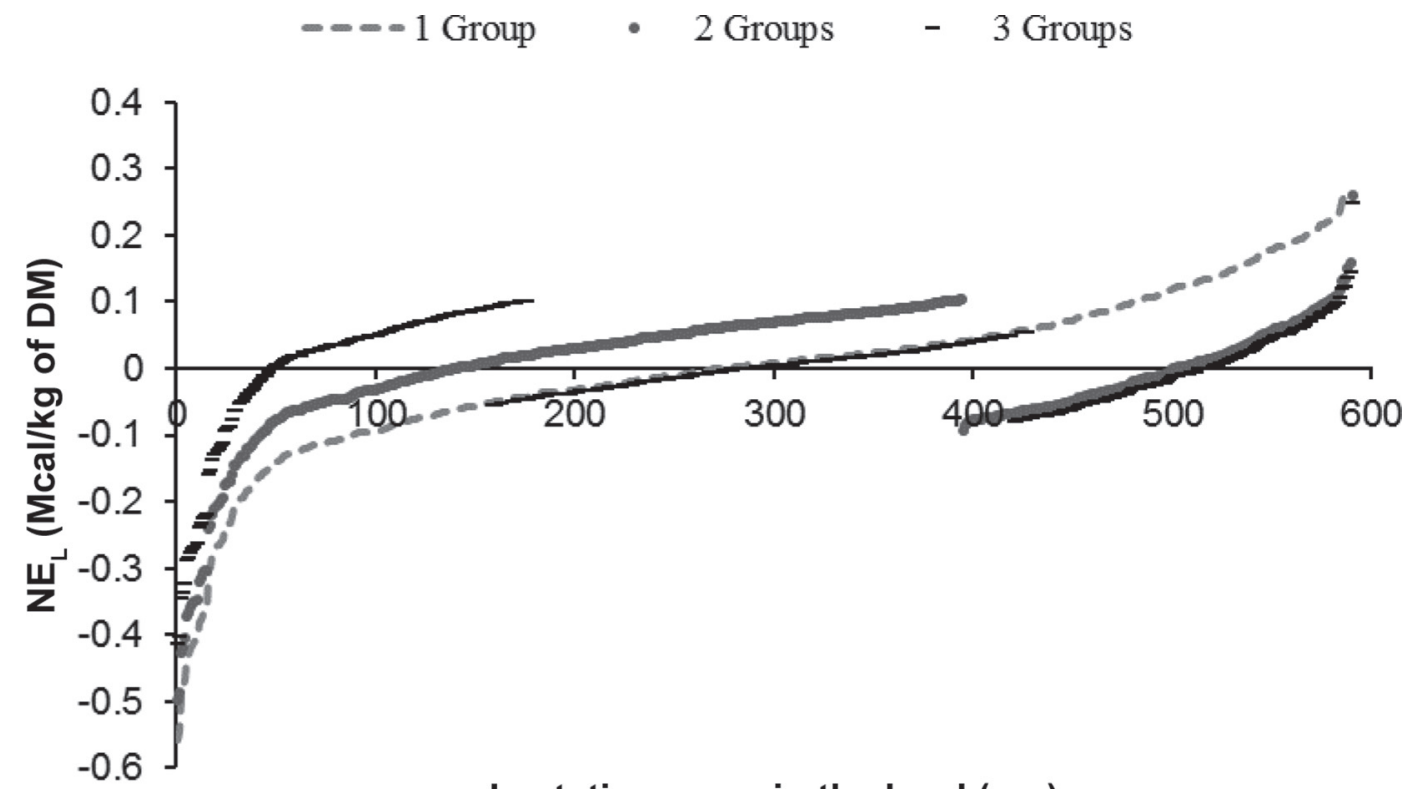

\section{Lactating cows in the herd (no.)}

Figure 4. Difference between provided and required $\mathrm{NE}_{\mathrm{L}}$ concentration under 1, 2, or 3 nutritional groups based on the diet offered at the average $\mathrm{NE}_{\mathrm{L}}$ concentration of the group. The figure is based on 592 lactating cows (all lactating cows minus fresh cows $<22 \mathrm{~d}$ postpartum) from the 787 -cow herd at $d=300$ in simulation. 
annual IOFC (\$/cow per yr) of 3 nutritional groups were $\$ 21, \$ 33$, and $\$ 40$ higher than that of 2 groups at production levels of $8,000,9,000$, and $10,000 \mathrm{~kg} /$ cow per 305-d lactation, respectively. In the current study, the average gain over all 5 herds from 2 groups to 3 groups was $\$ 8 /$ cow per year, which is lower than the reported values in Williams and Oltenacu (1992). This might be because Williams and Oltenacu (1992) included the effect of different milk production levels in the herd, but here, to focus on the value of grouping, we tried to exclude the effect of different milk production as much as possible. Here, most of the economic gain was observed in the first grouping (from 1 group to 2 groups). St-Pierre and Thraen (1999), using economic optimized lead factors for $\mathrm{CP}$ and $\mathrm{NE}_{\mathrm{L}}$ for different group numbers, calculated average economic gains $(\$ /$ cow per yr) of $\$ 44$ and $\$ 77$ when comparing 2 and 3 groups with 1 group, respectively. These values are comparable to those found in this study in the case of offering a diet of average $\mathrm{MP}+0.5 \mathrm{SD}$ and average MP+1SD. A study by Østergaard et al. (1996) used a dynamic stochastic simulation model to compare different grouping strategies under different reproductive and culling management. In that study, Scandinavian feed units (SFU) were used. Regrouping of the cows was triggered by a decrease in milk production levels after 24 wk postcalving. Thus, using SFU and consider- ing the setting of that study, feeding of the cow was not according to the calculated nutrient requirements but was specified by a feeding regimen of TMR with up to 3 different groups (Østergaard et al., 1996). Although the differences in the feeding systems make it difficult to compare the current study with that of Østergaard et al. (1996), they also showed that overall 1 group was inferior to other grouping strategies mainly due to the economic effect of lower milk production and higher amount of concentrate intake in 1 group (Østergaard et al., 1996). They also found that marginal net revenue per cow per year was lower under 1 group compared with 2 or 3 groups under all scenarios of milk production and reproductive and culling management. However, the economic difference due to good and bad reproductive and culling management was greater (Østergaard et al., 1996).

It should be noted that, in this study, we used the actual requirements of the cows to determine the offered diet concentration of $\mathrm{NE}_{\mathrm{L}}$ and $\mathrm{MP}$, and therefore no lead factor was used. This had a great effect on the overall economic value of a grouping strategy. We also speculate that not considering the herd structure and the dynamics of the herd throughout lactation, as was done in this study, could overestimate the economic gain of nutritional grouping. The average economic gain for 3 groups compared with 1 group without herd

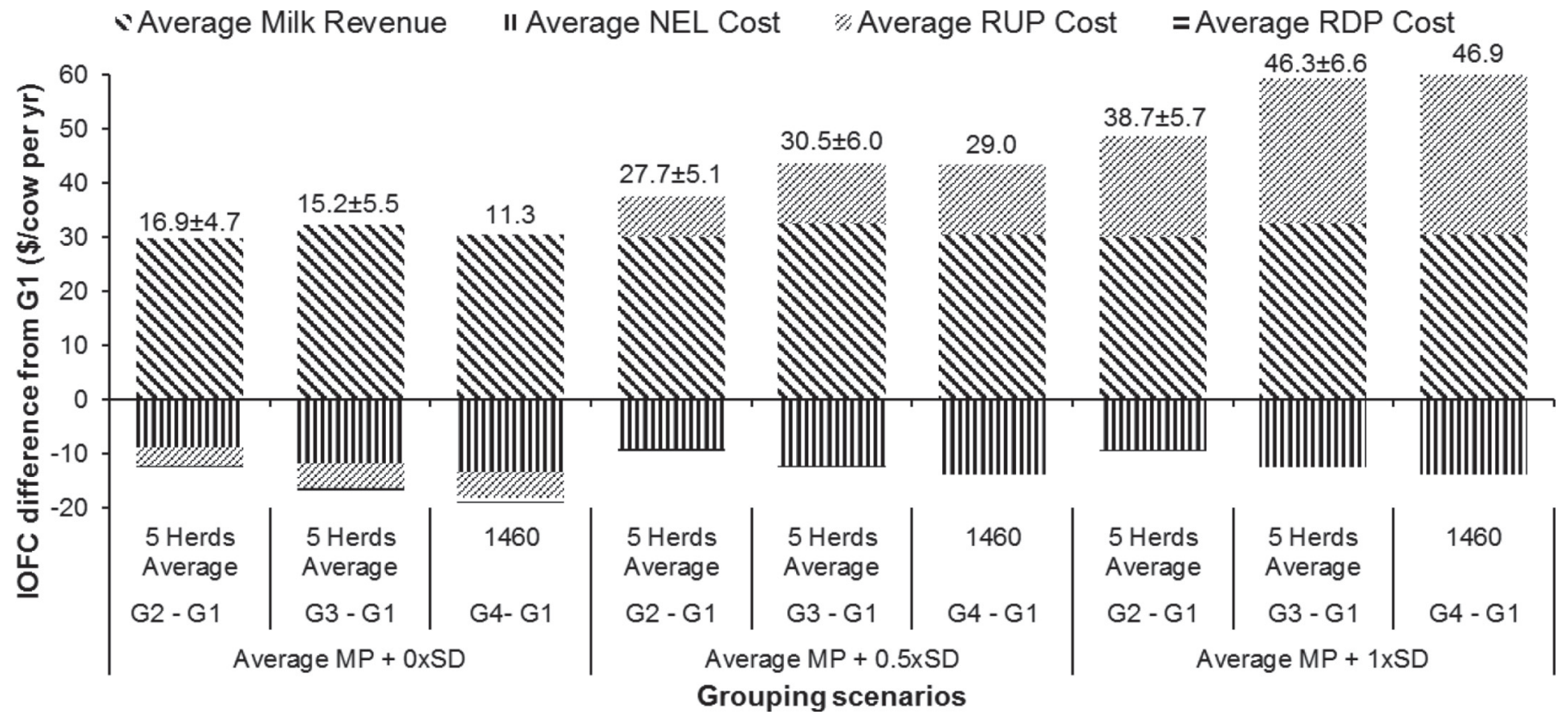

Figure 5. Average difference in income over feed cost (IOFC) of 2, 3, and 4 groups (G2, G3, and G4) and 1 group (G1). The average difference in IOFC is disaggregated in its components, which are RDP cost, RUP cost, $\mathrm{NE}_{\mathrm{L}}$ cost, and the milk revenue. The zero line is the average IOFC obtained by 1 group under different MP scenarios and were equal to $\$ 2,883, \$ 2,852$, and $\$ 2,822$ for diet formulated at average MP, average $\mathrm{MP}+0.5 \times \mathrm{SD}$, and average $\mathrm{MP}+1 \times \mathrm{SD}$, respectively. The labels on top of the bars are the average extra $\mathrm{IOFC} \pm \mathrm{SD}$ (SD among the herds) above 1 group. Four nutritional groups were applied only to the largest herd (1,460-cow herd). 
dynamics was reported to be $\$ 396 /$ cow per year in Cabrera et al. (2012).

The other important factor in economic evaluation of grouping lactating cows is the extra labor needed to formulate, prepare, and deliver feeds, and the extra costs of running mixers for preparing the TMR for each group separately. In addition, there is a labor cost related to moving cows among groups. These costs are usually farm specific and vary among herds (Østergaard et al., 1996), and for simplification were not included in the current study. Overall, profitability and feasibility of nutritional grouping are highly farm and market dependent. Farm size has an effect on the feasibility of nutritional grouping. For example, the extra labor for regrouping and moving cows might be less important in larger herds than in smaller herds (Østergaard et al., 1996). Also, when market conditions determine high feed costs and low milk prices, nutritional grouping could be more economically appealing (Allen, 2008; Hutjens, 2013). Simulation studies (Pecsok et al., 1992; Williams and Oltenacu, 1992) have suggested dividing lactating cows into 3 nutritional groups for optimal efficiency. Results from this study corroborate those previous reports indicating that economic gain and efficiency increase up to 3 nutritional groups. Also, the rate of improvement of IOFC with each additional grouping followed the law of diminishing returns, and the highest relative gain was when changing from 1 to 2 nutritional groups.

\section{Formulated Diet}

The average $\mathrm{NE}_{\mathrm{L}}, \mathrm{RDP}$, and RUP concentrations in DM under 3 levels of offered MP concentrations are summarized in Table 4. These are the values obtained by averaging the values from 12 periods of the simulation over a year (monthly regrouping times) over 1,000 iterations of the simulation and for 5 different herds in the study. The formulated diet for 1 group had a concentration of $1.5 \mathrm{Mcal} / \mathrm{kg}$ of DM. Having more groups divides the cows into more homogeneous $\mathrm{NE}_{\mathrm{L}}$ concentration groups and hence higher and lower concentrations of $\mathrm{NE}_{\mathrm{L}}$ in the diet. A similar pattern was observed in RDP and RUP percentages in the diet. The reported $\mathrm{NE}_{\mathrm{L}}$ concentrations by McGilliard et al. (1983) using a clustering method with 2 groups were 1.62 (high) and 1.42 (low) Mcal/kg, which are comparable to those obtained here $(1.59$ and $1.41 \mathrm{Mcal} / \mathrm{kg}$, respectively). The optimal allocation of $\mathrm{NE}_{\mathrm{L}}$ concentration found in St-Pierre and Thraen (1999) was much less variable and higher than that reported here or in the McGilliard et al. (1983) study. The optimum allocation of $\mathrm{NE}_{\mathrm{L}}$ found in St-Pierre and Thraen (1999) study was $1.78(\mathrm{Mcal} / \mathrm{kg})$ in the 1 -group case and remained above 1.7 even in the case of 3 groups. Previous studies have used $\mathrm{CP}$ to estimate required protein in the group, whereas this study used the MP requirement of the cows. By converting RDP and RUP in Table 4 to CP (RDP + RUP/0.8), the obtained $\mathrm{CP} \%$ was higher than the reported optimum allocation of $\mathrm{CP} \%$ by St-Pierre and Thraen (1999), which used milk production as the proxy for diet formulations. In 1 group, the estimated range of $\mathrm{CP}$ was $18,18.5$, and $19 \%$ for average, $0.5 \mathrm{SD}$, and 1SD above average, respectively (Table 4 ), and the values are comparable to the optimum allocation of $\mathrm{CP}$ (17.7\%; St-Pierre and Thraen, 1999). The maximum CP\% was in the case of 4 groups, when separating the most elite animals from the other cows, and was equal to $20 \%$. In the current study, the difference of CP\% in different group numbers were approximately 2,3 , and 3.8 percentage points for 2,3 , and 4 groups, respectively. The differences for the optimum allocation of CP reported by St-Pierre and Thraen (1999) were 1 and 2 percentage points for 2 and 3 groups, respectively.

\section{Captured Energy in Milk}

Percentage of total $\mathrm{NE}_{\mathrm{L}}$ consumed that was captured in milk is presented in Figure 6. This percentage showed a slight decrease with more groups and the values were similar among different numbers of groups for all the herds. The similarity of the percentage of total $\mathrm{NE}_{\mathrm{L}}$ intake that is captured in milk was also shown in a field trial study by Smith et al. (1978). The results of the current study could be explained by studying the detailed charts of the $\mathrm{NE}_{\mathrm{L}}$ concentration in the diet (Figure 7) and the distribution of the retained $\mathrm{BE}$ in terms of BCS (Figure 8). Average $\mathrm{NE}_{\mathrm{L}}$ and $\mathrm{MP}$ concentrations in the diet for all the cows in the 727-cow herd over all lactations for 1,000 replications are illustrated in Figure 7. A greater proportion of the cows in the herd were underfed in the case of 1 group than with more groups and therefore the total $\mathrm{NE}_{\mathrm{L}}$ consumption and milk yield (milk yield depended on the energy in the body as captured in BCS) for just 1 group was less than that with 2 and 3 groups. It should be noted that upper and lower bounds of BCS were restricted between 2.0 and 4.5. The gray lines in Figure 7 shows that utilizing 2 or 3 groups increased the diet $\mathrm{NE}_{\mathrm{L}}$ concentration in early lactation (the time that is most needed) until around $150 \mathrm{~d}$ postpartum. After this point, 2 and 3 groups had a lower $\mathrm{NE}_{\mathrm{L}}$ concentration in the diet than did 1 group. The overall lower $\mathrm{NE}_{\mathrm{L}}$ concentration required for late-lactation cows was generally lower than the higher $\mathrm{NE}_{\mathrm{L}}$ concentration required for early-lactation cows, and therefore the total $\mathrm{NE}_{\mathrm{L}}$ consumed was higher for multi-groups than for 1 group. Thus, the trend for percentage of total energy captured in milk was not 
consistent among herds. The sudden decrease in $\mathrm{NE}_{\mathrm{L}}$ concentration at $22 \mathrm{~d}$ postpartum (moving time of fresh groups to lactating groups) in 1 group should be noted. Cows in 1 group were then fed close to the average of the group $\mathrm{NE}_{\mathrm{L}}$ concentration of their requirements (approximately $1.5 \mathrm{Mcal} / \mathrm{kg}$ of $\mathrm{DM}$ ), which remained almost unchanged until around 300 DIM. At this point, the increasing proportion of dry cows and lowproducing, late-lactation cows reduced the average $\mathrm{NE}_{\mathrm{L}}$ concentration. On the other hand, in the case of 2 and 3 groups, after $22 \mathrm{~d}$ postpartum, there was a curvilinear pattern, which is explained by the fact that cows were fed closer to their requirements (and at higher concentrations than in 1 group) when the energy requirements were high. After passing the critical point of early lactation, $\mathrm{NE}_{\mathrm{L}}$ concentration decreased for 2 and 3 groups compared with 1 group. Two and 3 groups assure that late-lactation cows have enough energy in the diet but not much more than required. Overall, it is clear that use of 2 or 3 groups distributes $\mathrm{NE}_{\mathrm{L}}$ more efficiently based on DIM and productivity, which might increase overall $\mathrm{NE}_{\mathrm{L}}$ consumption in the herd (Figure 7).

Excess energy in late-lactation cows is associated with greater BCS and overconditioned cows that can have complications in the next lactation (Cameron et al., 1998). The effect of several nutritional groups on BW and BCS can be seen in Figure 8, which compares the effect of 1 and 3 nutritional groups on BW and BCS distributions of the 787-cow herd. The left panel of Figure 8 shows that the BW density plot of 2 grouping strategies (1 vs. 3 groups) does not differ considerably; they both have similar distributions. This indicates that use of 1 and 3 groups did not result in overall BW changes of the cows in the herds. The stable BW among different grouping numbers has also been found in field trials (Smith et al., 1978; Clark et al., 1980; Kroll et al., 1987). Right panel of Figure 8 illustrates the effect of nutritional grouping on the distribution of the cows' body energy content (BCS). The 1 group represented by a dark-shaded density plot has a different distri-

Table 4. Formulated diet components for different nutritional group numbers and scenarios obtained by averaging 5 herds $( \pm$ SD within herds) throughout the simulation period $(\mathrm{d}=1$ to $\mathrm{d}=365)$ and over 1,000 iterations

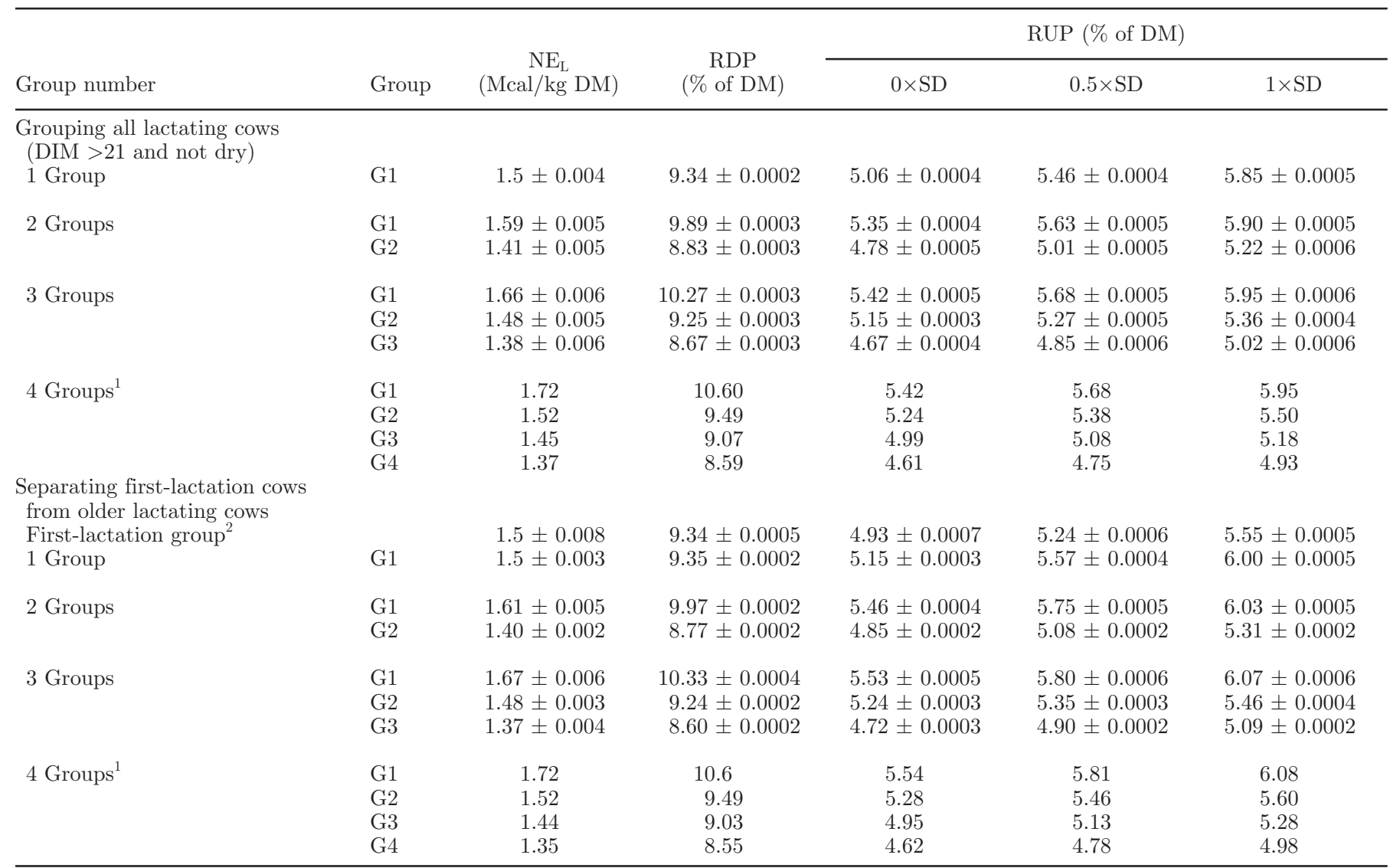

${ }^{1}$ Four groups were just experimented on the largest herd (1,460-cow herd).

${ }^{2}$ The average formulated diet for first-lactation cows separated from older cows was similar across all the grouping numbers and herds. 

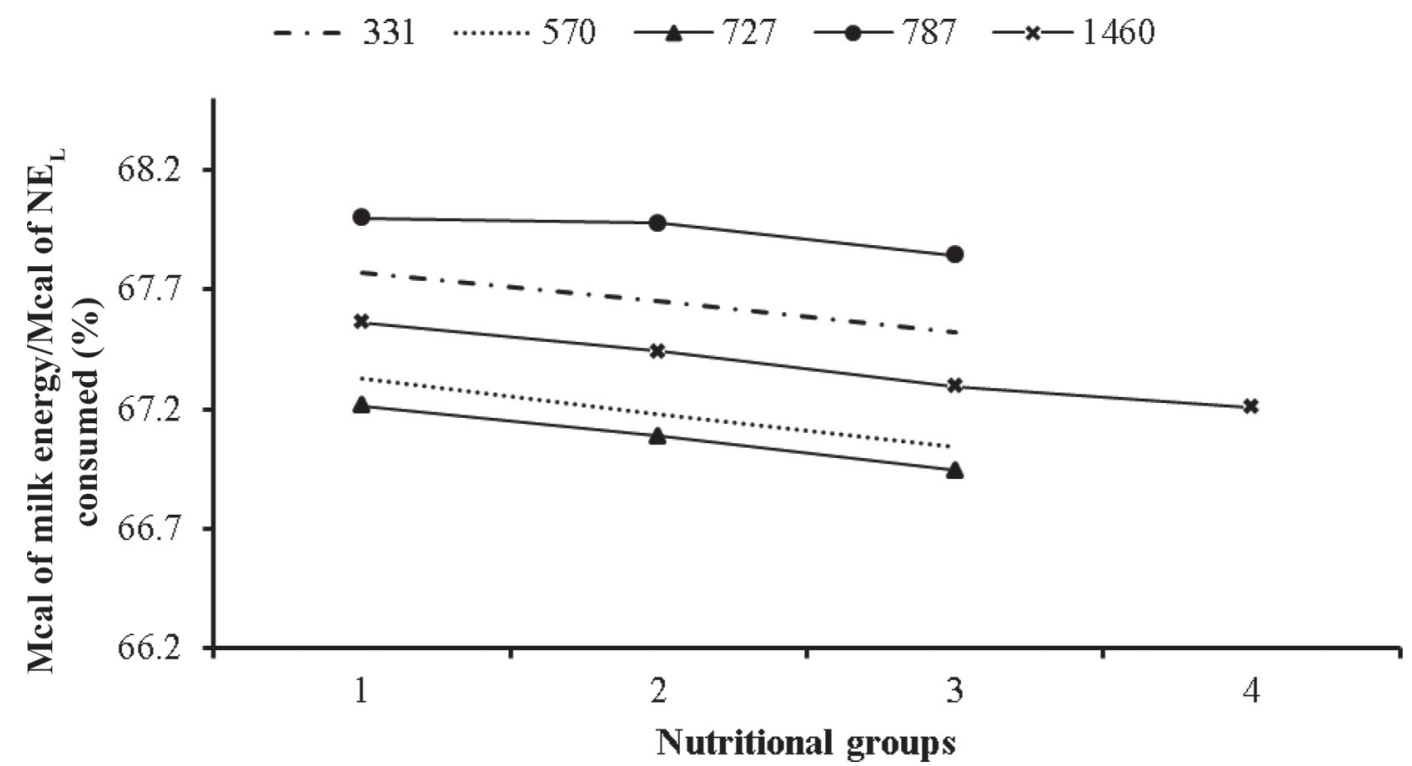

Figure 6. Percentage of total $\mathrm{NE}_{\mathrm{L}}$ consumed captured in milk according to number of groups and for the 5 different herds (labeled by the number of adult cows available in the herds).

bution than 3 groups (light shading). With 1 group, the distribution is thick-tailed, which means the model projects that many cows that are either underconditioned $(\mathrm{BCS}=2.0)$ or overconditioned $(\mathrm{BCS}=4.5)$, and it has a mode around $\mathrm{BCS}=2.75$. On the other hand, use of 3 groups shows a rather normal distribution curve with the mode around BCS $=3.25$. Similar distribution was observed in the case of 2 groups and in the other studied herds (data not shown). Having 2 or
3 groups appears to ensure that the consumed energy is better distributed promoting healthier cows.

\section{Captured N in Milk}

Percentage of total $\mathrm{N}$ consumed that was captured in milk is depicted in Figure 9. It is clear that percentage of $\mathrm{N}$ captured in milk increases with the number of groups at different slopes. Most of the gain was cap-

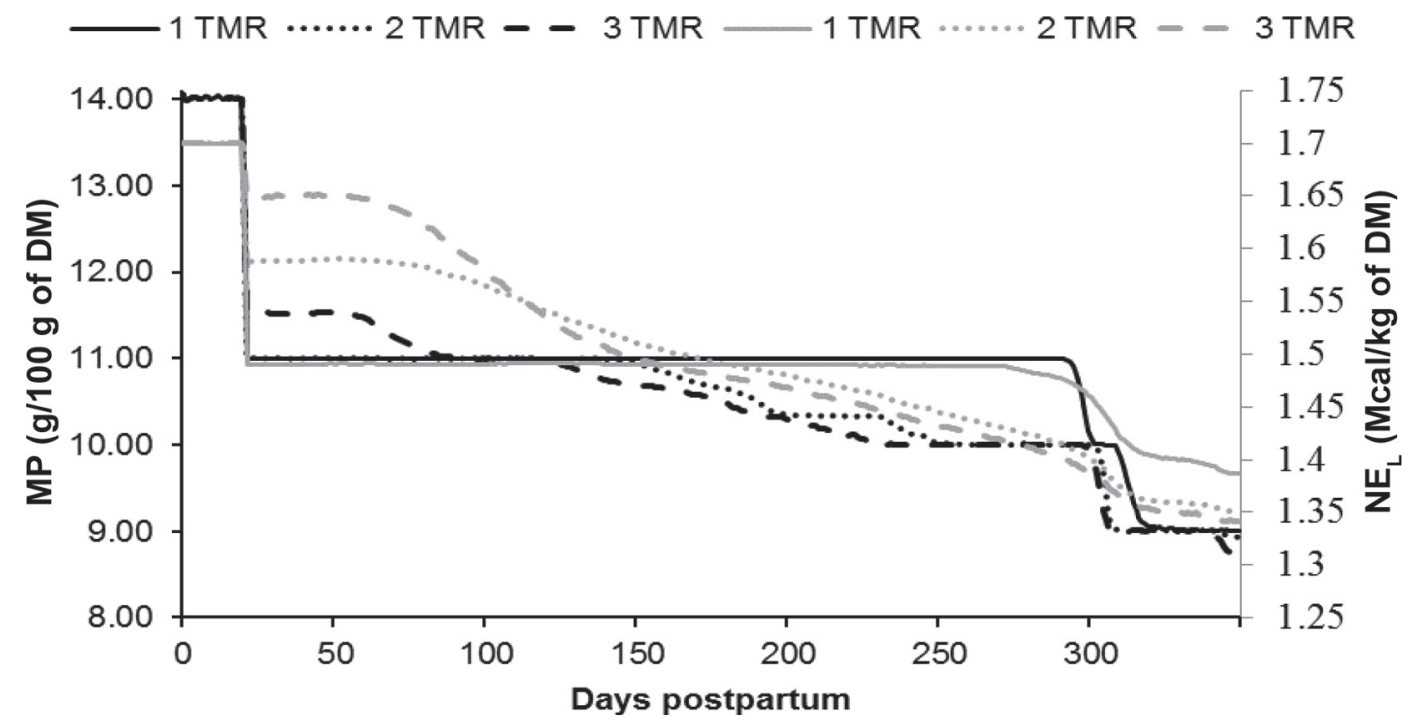

Figure 7. Offered diet average $\mathrm{NE}_{\mathrm{L}}$ (gray curves) and MP (black curves) after calving for the 727-cow herd under different number of nutritional groups from 1,000 replications. 

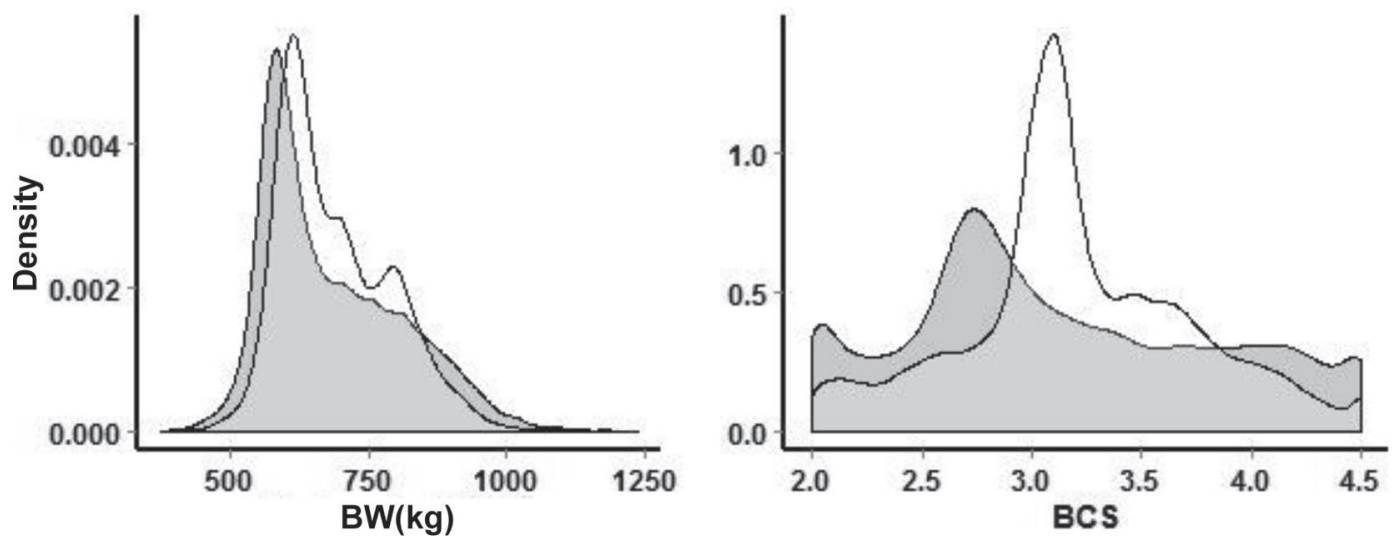

Figure 8. Body weight (left) and BCS (right) density plot created from aggregating all the cows from 1,000 replications from the 787-cow herd for 1 (dark shading) and 3 (light shading) nutritional groups. The average \pm SD for 1 and 3 nutritional groups are $3.0 \pm 0.7$ and $3.25 \pm$ 0.5 , respectively. Total area under the curves adds to 1 .

tured when moving to 2 nutritional groups. To depict the source of these higher percentages of $\mathrm{N}$ captured in milk, black lines in Figure 7 are provided. Figure 7 illustrates the actual MP offered in the diet $(\mathrm{g} / 100 \mathrm{~g}$ of DM) under different grouping strategies for the 727cow herd. The overall trend is similar to the provided $\mathrm{NE}_{\mathrm{L}}$ in the diet, as previously discussed. Until $21 \mathrm{~d}$ postpartum, all cows were fed a high concentrate diet with $14 \mathrm{~g}$ of MP/100 $\mathrm{g}$ of DM regardless of the grouping strategy. After $21 \mathrm{~d}$ postpartum, cows were moved to optional groups, which enabled the model to group them based on their requirements and number of groups under study. In the 1 group case, the MP consumption decreased to $11 \mathrm{~g} / 100 \mathrm{~g}$ of $\mathrm{DM}$, and stayed at the same level until about $300 \mathrm{~d}$ postpartum, when it decreased consistently through the rest of the lactation. However, in 2 and 3 groups, the provided MP in the diet was closer to the actual requirements. Therefore, with 2 or 3 groups, cows were fed more MP until about $100 \mathrm{~d}$ postpartum and thereafter fed lesser MP than the 1-group case. This higher $\mathrm{N}$ consumption in late lactation for 1 group compared with more groups is consistent with the literature (VandeHaar, 2014). Having 3 groups and formulating the diet at $1 \mathrm{SD}$ above the MP average improved $\mathrm{N}$ efficiency by $2.7 \%$ on average. The corresponding value in St-Pierre and Thraen (1999) was $5.8 \%$. The reason for this discrepancy could be attributed to the differences in the modeling framework and the underlying assumptions between the 2 studies. In this study, we strived to model the whole herd throughout time, while tracking all the information regarding the groupings and changes in BW and BCS. St-Pierre and Thraen (1999) simulated the actual $\mathrm{CP}$ and $\mathrm{NE}_{\mathrm{L}}$ requirements of the cows without considering the herd dynamics.
The main economic gain of having more groups could be attributed to an increased percentage of $\mathrm{N}$ captured in milk, which in turn decreases feed cost related to RUP. Having more groups clearly improves the percentage of $\mathrm{N}$ captured in milk (Figure 9), which, at the same time, improves environmental stewardship by decreasing the amount of N excreted (VandeHaar, 2014).

\section{Scenario Analyses}

Table 5 presents the results from scenario analyses on the input price, inclusion of milk loss, and separation of the first-lactation cows from older cows. The results show that even in the worst economic conditions (lowest milk price with highest nutrient costs), grouping cows had a similar average IOFC gain compared with the base scenario. Comparing the base and best case scenarios over all herds, the average IOFC gain $(\$ / \mathrm{cow}$ per yr) was $\$ 6$ higher in 2 groups and $\$ 4$ in 3 groups. Comparing the IOFC gain ( $\$ /$ cow per yr) of 2 and 3 groups, the relative gain was highest in the worst case scenario $(\$ 10)$ and the lowest relative IOFC gain of having 3 groups instead of 2 groups was under the best case scenario $(\$ 6)$. This emphasizes the importance of grouping lactating cows in tough economic conditions, when the milk price is low compared with feed price. Even though the relative IOFC gain was greater in the worst conditions, the highest IOFC gain in absolute terms was when the milk price was high compared with feed costs (i.e., best case; Table 5)

Assumed milk loss (1.82 kg/d for $5 \mathrm{~d})$ due to regrouping decreased the average 5 herds' IOFC of 2 groups by $\$ 18 \pm 2$ across all the herds and by $\$ 20 \pm 1$ for 3 groups compared with 1 group (base scenario; Table 5). The data showed that even under the assumption of 
milk loss because of regrouping, there is still an overall economic gain. However, considering milk loss for all cows, as was assumed in this study, resulted in the lowest economic gain among all the scenarios, including the worst case scenario. The amount of IOFC gain $(\$ /$ cow per yr) ranged from $\$ 14$ to $\$ 32$ when comparing 1 and 2 groups and the IOFC gain ranged from $\$ 19$ to $\$ 38$ when comparing 1 and 3 groups. The amount of loss depended on the number of times cows were reassigned to a different group, and it was affected by cow characteristics (i.e., milk production and DIM that determine cow requirements) and the nutrient requirement variations among the cows in the groups. The trend when having milk loss because of regrouping was consistent with the base scenario in that the largest gain was observed between 1 and 2 groups. Smith et al. (1978), in a field study, compared lactating cows grouped into 1 and 2 groups. In that study, the average decline in milk production was found to be $2 \mathrm{~kg} / \mathrm{cow}$ per day for $7 \mathrm{~d}$, and this amount was affected by parity (less milk loss for first-lactation compared with older cows). Even with this amount of milk loss, the IOFC of 2 groups was $\$ 30 /$ cow per year greater than that of 1 group, as a result of less concentrate fed (Smith et al., 1978). This amount of gain in IOFC is in the range of values found in this study. In another field study by Zwald and Shaver (2012) the milk loss due to change in groups was reported to be insignificant. Overall, the effects of grouping on the milk production of the cows in inconclusive (Clark et al., 1980) and, based on the 2 field studies mentioned above (Smith et al., 1978;
Zwald and Shaver, 2012), it seems that the assumed amount of milk loss in this study (total of $9.1 \mathrm{~kg}$ in $5 \mathrm{~d}$ ) could be either underestimated or overestimated. Thus, the true amount of milk loss is unknown, and studies have shown that it could be affected by parity (Smith et al., 1978) and could vary among cows based on their DIM (Kroll et al., 1987) and possibly their characteristics. It seems safe to assume that not every cow might experience the same amount of loss and the duration could vary among cows based on their characteristics. However, the amount of saving in the feed cost due to grouping could exceed the loss in the milk production (Smith et al., 1978; Clark et al., 1980).

Adding first-lactation cows as a separate group also affected the economics of nutritional groupings and is summarized in Table 5. The average IOFC gain among all the herds was lower than that of the base scenario by $\$ 7 \pm 2$ /cow per year. This smaller gain when separating first-lactation cows was mostly due to the fact that having a separate group of first-lactation animals ensures a diet tailored more closely for those cows and older cows, similar to having a separate nutritional group. Table 4 summarizes the formulated diet when separating first-lactation cows into their own group. Regardless of the number of groups, the formulated diet of first-lactation cows was the same across different group numbers and herds. However, separating the first-lactation cows into a group increased the nutrient concentration of the diet of older cow groups, thus the higher feed costs (higher RUP costs) and smaller IOFC gain in this scenario. It should be mentioned that the

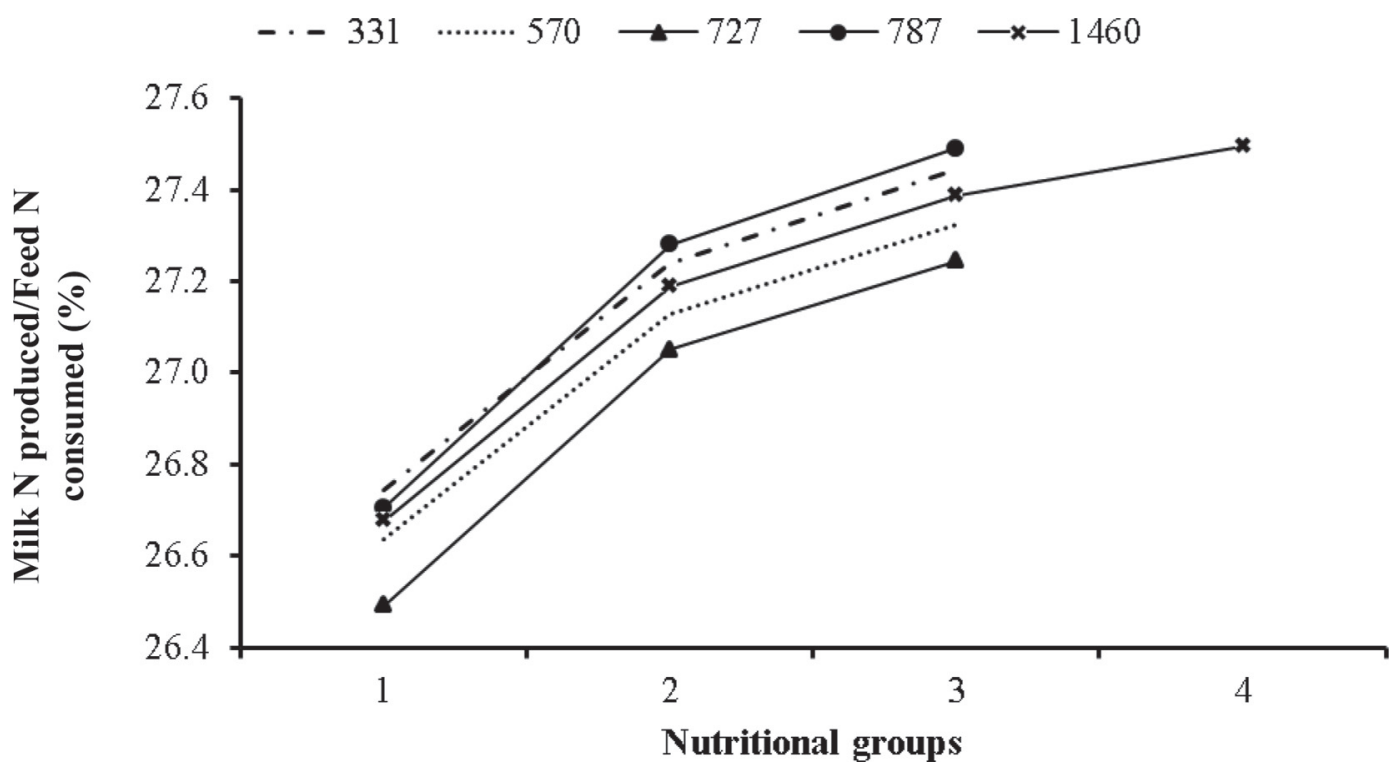

Figure 9. Percentage of total consumed N captured in milk according to number of groups and for 5 different herds. Label numbers represent the herd size in number of cows. 
model did not consider the possible benefit of separating first-lactation animals due to social hierarchy among the younger cows and older cows, which could result in decreases in feed intake and milk production of first-lactation cows (Botheras, 2007). Considering this issue could increase the reported economic gain of separately grouping first-lactation cows.

\section{Limitations}

The model described here attempted to consider most of the details relevant to nutritional grouping. However, like any other model, it is an abstract version of the actual herds and therefore subject to limitations. In this study, we used NRC (2001) equations to estimate the protein and energy requirements of the cows, which is a nutrient requirement-based system (St-Pierre and Thraen, 1999). This system uses physiological status, such as milk production and pregnancy status, of the cows as inputs and produces the energy and protein requirements of the given cow (St-Pierre and Thraen, 1999). This is different from the production-response system, in which the milk production and physiological status of the cows are the output of the model driven by the amount of nutrients provided in the diet. The latter system would be preferred due to the inherent relevancy of the input and outputs in the cows. Nevertheless, in this study, we used the nutrient requirements and DMI equations from NRC (2001) to estimate the energy intake of the cows. The DMI equation adjusts DMI based only on BW and milk energy yield, with a discount in early lactation. In this equation, diet energy density does not affect DMI, which could result in increased energy intake. Currently, the appropriate mathematical formulation for including dietary energy density on the DMI of the cows is not available. Therefore, to control the energy intake of the cows in the current study, the BCS of the cows was arbitrarily bounded between 2.0

Table 5. Economic gain in income over feed costs (IOFC) of grouping strategies under 5 studied scenarios

\begin{tabular}{|c|c|c|c|c|}
\hline \multirow[b]{2}{*}{ Herd size } & \multirow[b]{2}{*}{ Scenario } & \multicolumn{3}{|c|}{$\begin{array}{l}\text { Difference between grouping strategies } \\
\text { and } 1 \text { group }(\$ / \text { cow per yr })\end{array}$} \\
\hline & & 2 Groups & 3 Groups & 4 Groups \\
\hline \multirow[t]{5}{*}{$\overline{331}$} & Base $^{1}$ & 34.6 & 41.8 & - \\
\hline & Worst $^{2}$ & 32.0 & 41.7 & - \\
\hline & Best $^{3}$ & 39.3 & 44.2 & - \\
\hline & Milk loss ${ }^{4}$ & 13.9 & 22.4 & - \\
\hline & First lactation $^{5}$ & 31.9 & 38.0 & - \\
\hline \multirow[t]{5}{*}{570} & Base & 32.9 & 39.7 & - \\
\hline & Worst & 31.5 & 40.4 & - \\
\hline & Best & 36.5 & 41.1 & - \\
\hline & Milk loss & 13.5 & 18.7 & - \\
\hline & First lactation & 27.2 & 32.7 & - \\
\hline \multirow[t]{5}{*}{727} & Base & 40.6 & 47.9 & - \\
\hline & Worst & 37.1 & 46.1 & - \\
\hline & Best & 46.6 & 52.5 & - \\
\hline & Milk loss & 24.7 & 27.9 & - \\
\hline & First lactation & 32.4 & 37.3 & - \\
\hline \multirow[t]{5}{*}{787} & Base & 48.8 & 58.3 & - \\
\hline & Worst & 43.0 & 53.6 & - \\
\hline & Best & 58.0 & 66.5 & - \\
\hline & Milk loss & 32.3 & 37.9 & - \\
\hline & First lactation & 42.0 & 50.1 & - \\
\hline \multirow[t]{5}{*}{1,460} & Base & 36.4 & 43.5 & 46.9 \\
\hline & Worst & 33.8 & 42.9 & 47.4 \\
\hline & Best & 41.3 & 46.6 & 48.8 \\
\hline & Milk loss & 17.9 & 22.6 & 23.5 \\
\hline & First lactation & 29.7 & 35.7 & 38.5 \\
\hline \multicolumn{5}{|c|}{$\begin{array}{l}{ }^{1} \text { Base scenario running on the average } \mathrm{NE}_{\mathrm{L}} \text { concentration and average } \mathrm{MP}+1 \times \mathrm{SD} \text { with } 10 \text { yr average annual } \\
\text { milk price }(\$ 0.39 / \mathrm{kg}) \text { and nutrient costs }\left(\mathrm{NE}_{\mathrm{L}}=\$ 0.1 / \mathrm{Mcal}, \mathrm{RDP}=\$ 0.18 / \mathrm{kg} \text {, and } \mathrm{RUP}=\$ 1.04 / \mathrm{kg}\right) \text {. }\end{array}$} \\
\hline \multicolumn{5}{|c|}{$\begin{array}{l}{ }^{2} \text { Worst case scenario couples the lowest milk price with the highest feed price from historical } 10 \mathrm{yr} \text { annual aver- } \\
\text { age (milk price }=\$ 0.29 / \mathrm{kg}, \mathrm{NE}_{\mathrm{L}}=\$ 0.14 / \mathrm{Mcal}, \mathrm{RDP}=\$ 0.26 / \mathrm{kg} \text {, and RUP }=\$ 1.52 / \mathrm{kg} \text { ). }\end{array}$} \\
\hline \multicolumn{5}{|c|}{$\begin{array}{l}{ }^{3} \text { Best case scenario couples the highest milk price with the lowest feed price from historical } 10 \mathrm{yr} \text { annual aver- } \\
\text { age }\left(\text { milk price }=\$ 0.52 / \mathrm{kg}, \mathrm{NE}_{\mathrm{L}}=\$ 0.05 / \text { Mcal, RDP }=\$ 0.09 / \mathrm{kg} \text {, and RUP }=\$ 0.52 / \mathrm{kg} \text { ). }\right.\end{array}$} \\
\hline \multicolumn{5}{|c|}{${ }^{4}$ Adding $5 \mathrm{~d}$ of $1.82 \mathrm{~kg} / \mathrm{d}$ milk loss for cows changing to another group under base scenario. } \\
\hline \multicolumn{5}{|c|}{$\begin{array}{l}{ }^{5} \text { Including first-lactation cows as a separate obligatory group under base scenario. In this scenario, the one } \\
\text { group itself has } 2 \text { groups: first-lactating cows and } \geq \text { second-lactating cows. Thus, in addition to the number of } \\
\text { groups for older cows, one group is just for first-lactation cows. }\end{array}$} \\
\hline
\end{tabular}


and 4.5. Cows with BCS falling below 2.0 were assumed to decrease their milk production, and cows with BCS exceeding 4.5 limited their DMI. In reality, there seems to be a subtle mechanism for regulating production and DMI according to energy balance. This behavior of the model could be improved if data to describe the DMI regulation based on the nutrient requirements and energy density of the diet were available.

Furthermore, the current model does not consider the effect of low (high) BCS during dry periods on the next lactation production, health issues, or reproductive performance. These effects have been reported in many studies, as summarized by Roche et al. (2009) . Lower BCS is associated with less milk production and lower conception rate in the next lactation. High BCS is linked to many metabolic disorders, including fatty liver, ketosis, and displaced abomasum (Cameron et al., 1998). Thus, no correlation between different events and productivity and performance of the cows has been assumed. Because of these, the figures reported herein could be underestimations of the true economic and efficiency gains from nutritional grouping.

Also, the developed model regrouped all lactating cows monthly. However, the time for regrouping itself could be triggered based on a criterion in the group to find the optimum time for regrouping. For example, Østergaard et al. (1996) used daily milk thresholds to determine regrouping time in the simulation herds.

Additionally, the effect of separating first-lactation animals in this study could include an underestimation because separating first-lactation cows from mature cows could increase the milk production of the firstlactation cows (Sniffen et al., 1993) due to decreased dominance effects (adult vs. first-lactation cows), which were not included in the current study.

\section{CONCLUSIONS}

A dynamic, stochastic Monte Carlo simulation model was used to quantify the economic benefit of nutritional grouping on 5 selected dairy herds with different sizes and structures. The majority of economic gains from nutritional grouping for lactating cows could be obtained by having 2 nutritional groups (instead of 1 group besides the fresh cow group). Adding a third group increased the gains compared with 2 groups, but on a much smaller scale, and such practice might not be justified based on the additional costs potentially incurred. The economic gain was mainly due to higher milk production and lower RUP costs, and gain was emphasized in tough economic conditions. The effect of a possible constant milk loss when regrouping cows could have a negative effect, but even after considering such a situation, a positive economic gain was accrued.
Separating first-lactation cows could be considered a grouping strategy in itself.

\section{ACKNOWLEDGMENTS}

Funding for this project was provided by Agriculture and Food Research Initiative Competitive Grant no. 2011-68004-30340 from the USDA National Institute of Food and Agriculture. This research was also supported by the USDA-University of Wisconsin Hatch Project No. WIS01699 to V. E. Cabrera.

\section{REFERENCES}

AgSource Cooperative Services. 2013. DHI Benchmarks. Revised January 1, 2013. Accessed Dec. 20, 2013. http://agsource.crinet.com/ page $849 /$ DHIBenchmarks.

Allen, M. 2008. Time to regroup. Michigan Dairy Review. Accessed Nov. 23, 2015. https://msu.edu/ mdr/vol13no2/allen.html.

Allen, M. S. 2009. Grouping to increase milk yield and decrease feed costs. 20th Annual Tri-State Dairy Nutrition Conference. Ohio State University Press, Columbus.

Allore, H. G., L. W. Schruben, H. N. Erb, and P. A. Oltenacu. 1998. Design and validation of a dynamic discrete event stochastic simulation model of mastitis control in dairy herds. J. Dairy Sci. 81:703-717.

Bach, A. 2014. Precision feeding to increase efficiency for milk production. West. Can. Dairy Semin. Adv. Dairy Technol. 26:177-189.

Banks, J., J. S. Carson, B. L. Nelson, and D. N. Nicol. 2009. Pages 468-470 in Discrete-Event System Simulation. 5th ed. Prentice Hall, Upper Saddle River, NJ.

Botheras, N. 2007. The feeding behavior of dairy cows: Considerations to improve cow welfare and productivity. eXtension. Accessed Jul. 19, 2010. http://www.extension.org/pages/25472/the-feedingbehavior-of-dairy-cows:considerations-to-improve-cow-welfareand-productivity\#.Va-HUmCpS1k.

Brakel, W. J., and R. A. Leis. 1976. Impact of social disorganization on behavior, milk yield, and body weight of dairy cows. J. Dairy Sci. 59:716-721.

Cabrera, V. E., F. Contreras, R. D. Shaver, and L. E. Armentano. 2012. Grouping strategies for feeding lactating dairy cattle. Grouping strategies for feeding lactating dairy cattle. Pages $40-44$ in Proc. Four-State Dairy Nutrition and Management Conference, Dubuque, IA. Wisconsin Agri-business Association, Madison.

Cabrera, V. E., and A. S. Kalantari. 2014. Strategies to improve economic efficiency of the dairy. West. Can. Dairy Semin. Adv. Dairy Technol. 26:45-55.

Cameron, R. E., P. B. Dyk, T. H. Herdt, J. B. Kaneene, R. Miller, H F. Bucholtz, J. S. Liesman, M. J. VandeHaar, and R. S. Emery. 1998. Dry cow diet, management, and energy balance as risk factors for displaced abomasum in high producing dairy herds. J. Dairy Sci. 81:132-139.

Clark, P. W., R. E. Rickets, and G. F. Krause. 1977. Effects on milk yield of moving cows from group to group. J. Dairy Sci. 60:769772.

Clark, P. W., R. E. Ricketts, R. L. Belyea, and G. F. Krause. 1980. Feeding and managing dairy cows in three versus one production group. J. Dairy Sci. 63:1299-1308.

Contreras-Govea, F. E., V. E. Cabrera, L. E. Armentano, R. D. Shaver, and P. M. Crump. 2013. Constraints for nutritional grouping in Wisconsin dairy farms. J. Anim. Sci. 91(E-Suppl. 2):540. (Abstr.)

Contreras-Govea, F. E., V. E. Cabrera, L. E. Armentano, R. D. Shaver, P. M. Crump, D. K. Beede, and M. J. VandeHaar. 2015. Constraints for nutritional grouping in Wisconsin and Michigan dairy farms. J. Dairy Sci. 98:1336-1344.

Coppock, C. E. 1977. Feeding methods and grouping systems. J. Dairy Sci. 60:1327-1336. 
De Vries, A. 2001. Statistical process control charts applied to dairy herd reproduction. PhD Thesis. University of Minnesota, St. Paul.

De Vries, A. 2004. Economics of delayed replacement when cow performance is seasonal. J. Dairy Sci. 87:2947-2958.

Giordano, J. O., A. S. Kalantari, P. M. Fricke, M. C. Wiltbank, and V. E. Cabrera. 2012. A daily herd Markov-chain model to study the reproductive and economic impact of reproductive programs combining timed artificial insemination and estrus detection. J. Dairy Sci. 95:5442-5460.

Hasegawa, N., A. Nishiwaki, K. Sugawara, and I. Ito. 1997. The effects of social exchange between two groups of lactating primiparous heifers on milk production, dominance order, behavior and adrenocortical response. Appl. Anim. Behav. Sci. 51:15-27.

Hillier, F. S., and G. J. Lieberman. 1986. Introduction to Operations Research. 4th ed. Holden-Day Inc., Oakland, CA.

Hutjens, M. F. 2013. Is a one TMR approach right? Pages 185-190 in Proc. Western Dairy Management Conf. Accessed Nov. 23, 2015. http://www.wdmc.org/2009/Is\%20a\%20One\%20TMR\%20Approach\%20Right.pdf.

Kroll, O., J. B. Owen, and C. J. Whitaker. 1987. Grouping and complete diet composition in relation to parity and potential yield in dairy cows. J. Agric. Sci. 108:281-291.

McGilliard, M. L., J. M. Swisher, and R. E. James. 1983. Grouping lactating cows by nutritional requirements for feeding. J. Dairy Sci. 663:1084-1093.

NRC. 2001. Nutrient Requirements of Dairy Cattle. 7th rev. ed. National Academies Press, Washington, DC.

Oltenacu, P. A., R. A. Milligan, T. R. Rounsaville, and R. H. Foote. 1980. Modelling reproduction in a herd of dairy cattle. Agric. Syst. 5:193-205

Østergaard, S. J., T. Sørensen, J. Hindhede, and A. R. Kristensen. 1996. Technical and economic effects of feeding one vs. multiple total mixed rations estimated by stochastic simulation under different dairy herd and management characteristics. Livest. Prod. Sci. 45:23-33.

Pecsok, S. R., M. L. McGilliard, R. E. James, T. G. Johnson, and J. B. Holter. 1992. Estimating production benefits through simulation of group and individual feeding of dairy cows. J. Dairy Sci. 75:1604-1615

Pinedo, P. J., A. De Vries, and D. W. Web. 2010. Dynamics of culling risk with disposal codes reported by dairy herd improvement dairy herds. J. Dairy Sci. 93:2250-2261.

Roche, J. R., N. C. Friggens, J. K. Kay, M. W. Fisher, K. J. Stafford, and D. P. Berry. 2009. Invited review: body condition score and its association with dairy cow productivity, health, and welfare. J. Dairy Sci. 92:5769-5801.

Shaffer, M. J., P. N. S. Bartling, and J. C. A. Ii. 2000. Object-oriented simulation of integrated whole farms: GPFARM framework. Comput. Electron. Agric. 28:29-49.
Smith, N. E. 1976. Maximizing income over feed costs: Evaluation of production response relationships. J. Dairy Sci. 59:1193.

Smith, N. E., and C. E. Coppock. 1974. Group feeding complete feeds to dairy cattle. Page 55 in Proc. Cornell Nutr. Conf., Cornell University, Ithaca, NY. Cornell University Press, Ithaca, NY.

Smith, N. E., G. R. Ufford, C. E. Coppock, and W. G. Merrill. 1978. One group versus two group system for lactating cows fed complete rations. J. Dairy Sci. 61:1138-1145.

Sniffen, C. J., R. W. Beverly, C. S. Mooney, M. B. Roe, A. L. Skidmore, and J. R. Black. 1993. Nutrient requirements versus supply in the dairy cow: Strategies to account for variability. J. Dairy Sci. $76: 3160-3178$

St-Pierre, N. R., and C. S. Thraen. 1999. Animal grouping strategies, sources of variation, and economic factors affecting nutrient balance on dairy farms. J. Anim. Sci. 77:72-83.

Stallings, C. C. 2011. Feeding cows with increasing feed prices: Efficiencies, feed options, and quality control. Pages 40-45 in Proc. 47th Florida Dairy Prod. Conf., Gainesville, FL.

Stallings, C. C., and M. L. McGilliard. 1984. Leading factors for total mixed ration formulation. J. Dairy Sci. 67:902-907.

van Arendonk, J. A. M. 1985. Studies on the replacement policies in dairy cattle. II. Optimum policy and influence of changes in production and prices. Livest. Prod. Sci. 13:101-121.

VandeHaar, M. J. 2014. Feeding and breeding for a more efficient cow. West. Can. Dairy Semin. Adv. Dairy Technol. 26:17-30.

Varga, G. A. 2010. Why use metabolizable protein for ration balancing? Accessed Nov. 23, 2015. http://www.extension. org/pages / 26135/why-use-metabolizable-protein-for-rationbalancing\#.VDKSIfldVEI.

von Keyserlingk, M. A., G. D. Olenick, and D. M. Weary. 2008. Acute behavioral effects of regrouping cows. J. Dairy Sci. 91:1011-1016.

Weiss, B. 2014. Setting nutrient specifications for formulating diets for groups of lactating dairy cows. Nov. 23, 2015. http://www. extension.org/pages/70124/setting-nutrient-specifications-forformulating-diets-for-groups-of-lactating-dairy-cows \#.VDKX2_ ldVEI.

Williams, C. B., and P. A. Oltenacu. 1992. Evaluation of criteria used to group lactating cows using a dairy production model. J. Dairy Sci. $75: 155-160$

Wood, P. D. P. 1967. Algebraic model of the lactation curve in cattle. Nature 216:164-165.

Zwald, A., and R. D. Shaver. 2012. Case study: Effect of pen change on milk yield by dairy cows in 2 commercial herds. Prof. Anim. Sci. 28:569-572. 